\title{
PREDICTING THE SHEAR-FLEXURAL STRENGTH OF SLENDER REINFORCED CONCRETE T AND I SHAPED BEAMS
}

Antoni Cladera ${ }^{1}$, Antonio Marí ${ }^{2}$, Carlos Ribas ${ }^{1}$, Jesús Bairán $^{2}$ and Eva Oller $^{2}$

(1) Department of Physics. University of Balearic Islands, Palma de Mallorca, Spain.

(2) Department of Construction Engineering, Universitat Politècnica de Catalunya, Barcelona, Spain.

Corresponding author: Antoni Cladera. Department of Physics, University of the Balearic Islands. Ctra. Valldemossa, km 7.5, Palma (Balearic Islands), Spain. Phone number: +34 97117 1378. E-mail:antoni.cladera@uib.es

\begin{abstract}
A mechanical model previously developed by the authors for the prediction of the shear-flexural strength of slender reinforced concrete beams with rectangular cross-section with or without stirrups has been extended to beams with $\mathrm{T}$ and I cross-sections. The effects of the section shape on each shear transfer action have been identified and incorporated into the corresponding equations. General expressions for strength verification and transverse reinforcement design have been derived. The contribution of the flanges to the shear strength is accounted for by means of an effective shear width, which depends on the section geometry and on the longitudinal reinforcement ratio. The effect of the vertical confinement stresses introduced by the shear reinforcement on the concrete web is also considered. The expressions derived are valid, as particular cases, for beams with inverted $\mathrm{T}$ or rectangular cross sections. The proposed equations have been checked with experimental results available in the literature, obtaining very good results. The simplicity, straightforwardness of application and the accuracy of the method make it suitable for daily engineering practice.
\end{abstract}

Keywords: Shear strength, reinforced concrete, T-beam, I-beam; stirrups, mechanical model, shear-flexure interaction. 


\section{INTRODUCTION}

T-shaped sections are widely used in RC beams and slabs because of their high flexural efficiency. The compression force generated by the bending moment is distributed along the effective width of the compression flange, $b$, which is higher than the web width, $b_{w}$, generating a lower compression block depth and a higher lever arm $z$, compared to that in a rectangular section of width $b=b_{w}$. In addition, the weight of the section is reduced with respect to a rectangular beam of the same top width.

Current codes usually separate the flexural and the shear resistant mechanisms: while bending is taken by the pair of forces $C$ (compression at the concrete chord) and $T$ (tension at the longitudinal reinforcement), shear is assumed to be taken by the web, by means of a truss mechanism, see Figure 1. Therefore, they do not consider any contribution of the flanges to the shear strength.

Such simplification does not represent with fidelity the behavior of slender RC members with T-shaped sections at ultimate load levels. Even in the case of rectangular sections, the truss analogy must be corrected to take into account that part of the shear is taken not only by the web, but also by the compressed concrete chord, by the longitudinal reinforcement (dowel action), by frictional forces along the crack length and by residual tensile stresses in the closest part of the cracks. All these aspects are included in a term called "concrete contribution to shear strength", $V_{c}$, which in case of slender beams does not include the "arch effect".

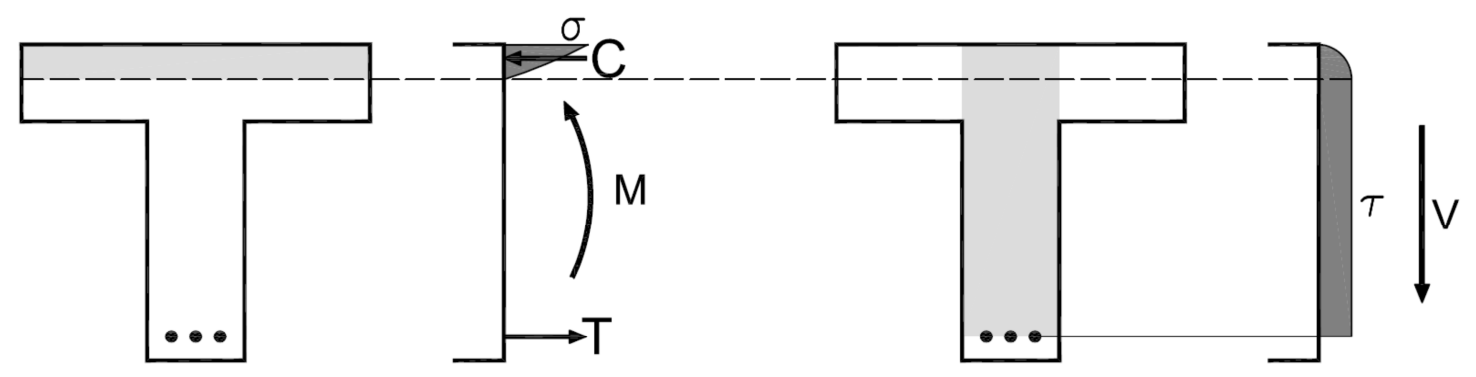

A)

B)

Figure 1. Uncoupled resistant mechanisms: A) Flexure. B) Shear.

In slender beams subjected to shear and bending, flexural cracks initiate at the tensile face, and subsequently develop inclined through the web. As the load increases, damage concentrates around the so-called critical shear crack [1], whose first branch arrives to the neighborhood of the flexural neutral axis. Under incremental loading, a second 
branch of the critical shear crack develops inside the concrete chord, which eventually connects the first branch of the crack and the point where the load is applied, producing failure, see Figure 2. This way of dividing the critical shear crack in two branches was also observed by Zararis and Papadakis [2].
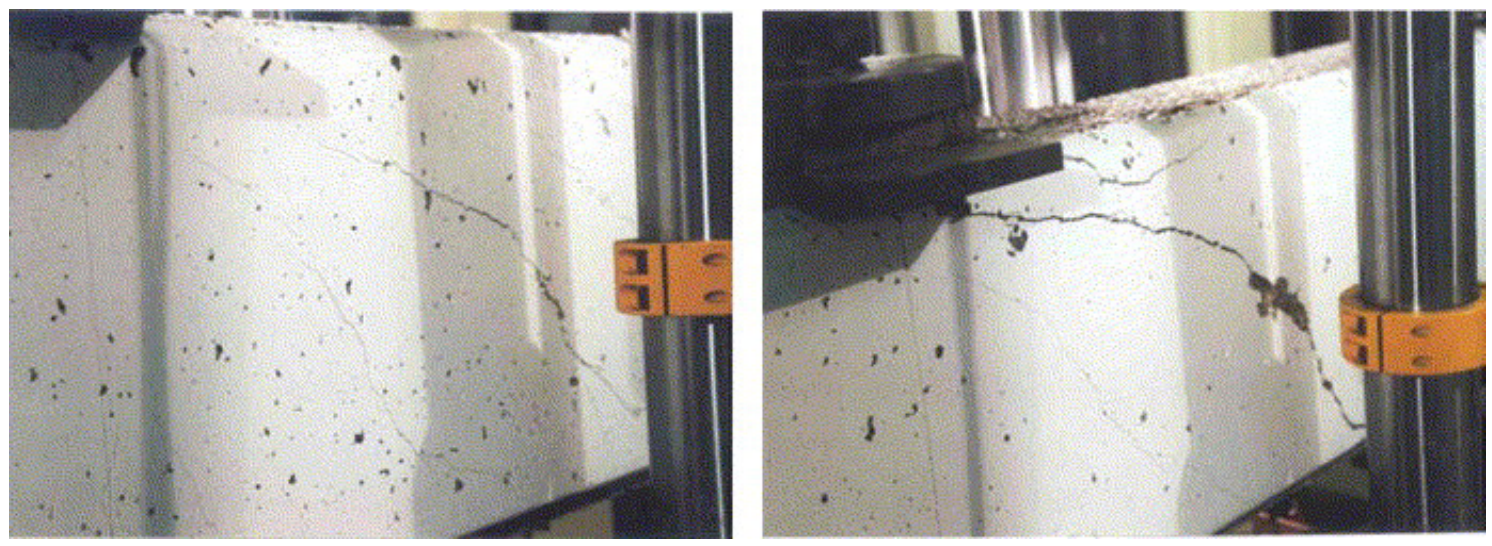

Figure 2. Cracking prior to failure and at failure in a rectangular beam with web reinforcement (photographs from the authors) [3].

As the load increases, the inclined cracks open and the contributions to shear strength of the frictional forces along the crack length and that of the residual tensile stresses diminish. The shear stresses along the critical crack decrease and they concentrate in the closest top part of the cracks and in the compression chord of the beam, especially after stirrups yield. In addition, as the load increases, the compression force $C$ and the normal stresses due to bending at the uncracked concrete chord increase, thus increasing the capacity of the concrete compression chord to resist shear stresses. Therefore, near the ultimate limit state, the shear resisted by the concrete compression chord becomes very relevant.

In the case of members with T-shaped sections this phenomenon is even more apparent because of two reasons. Firstly, the neutral axis depth of a T-shaped section is closer to the top compressed fiber. Therefore, for a given ratio $M / M_{c r}>1$, where $M$ is the applied moment and $M_{c r}$ is the cracking moment, and for the same reinforcement area and effective depth, the crack opening is higher in a T-shaped section beam than in a rectangular beam of the same web width, so the aggregate interlock is lower, see Figure 3. Secondly, the concrete flange of a T-shaped section produces that, once the shear stresses concentrate on it, the contribution to the shear strength of the concrete chord is higher than in a rectangular section of $b=b_{w}$, turning out in higher total shear strength, as can be seen in Figure 4. 


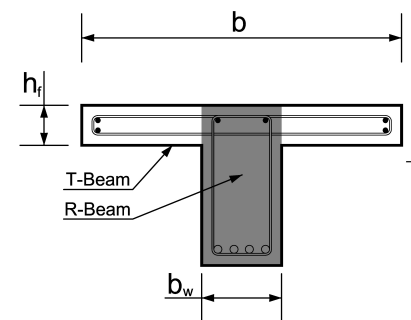

A)

Figure 3. Comparison between T-shaped section beam and rectangular beam. A) Sections. B) Crack pattern scheme of a rectangular beam. C) Crack pattern scheme of a $\mathrm{T}$ beam.

Experimental studies [4-9] show that a considerable increase in the shear strength of slender RC beams and slabs with T-shaped section takes place with respect to beams with equal height, web width and reinforcements amounts. Figure 4 shows that beams with $30 \mathrm{~cm}$ or wider flanges had about $25 \%$ greater ultimate strength than the rectangular beams [10]. This fact indicates that there exists some contribution of the compression flange which is being ignored in the current codes shear provisions.

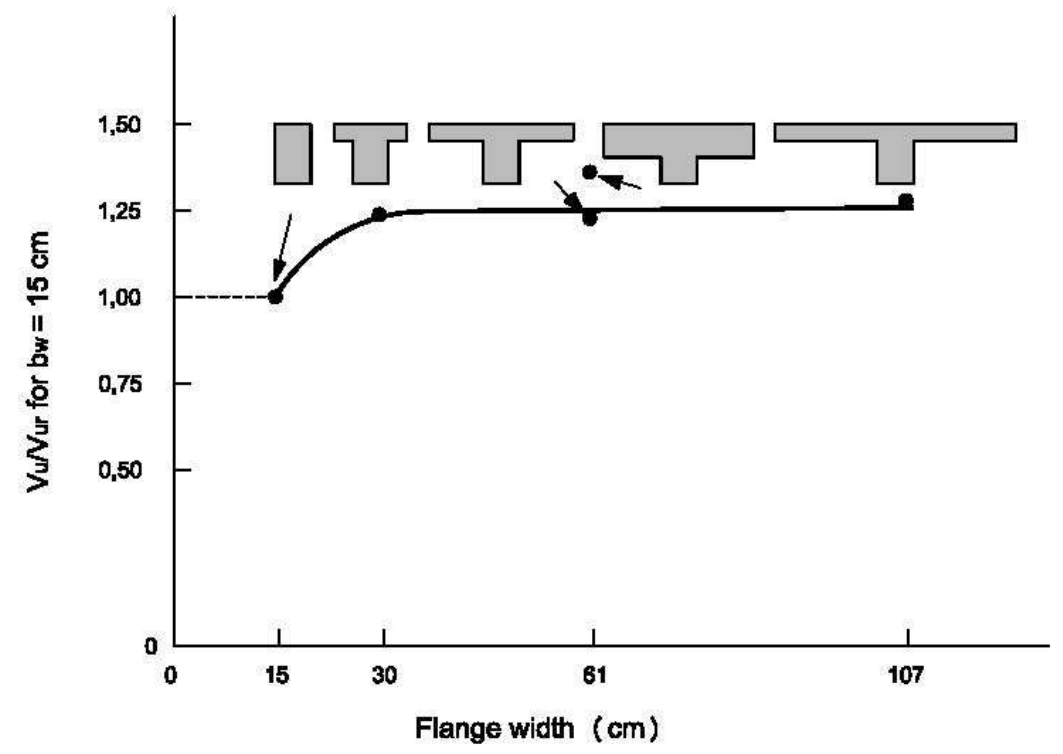

Figure 4. Effect of flange width, adapted from [10], based on an experimental campaign published in [7].

In addition, rigorous theoretical and numerical studies carried out [11-13] confirm such concentration of stresses towards the neighborhood of the crack tip and towards the concrete compression chord. Figure 5 shows the concrete shear stresses in a rectangular section at service and at ultimate load levels. In the case of $\mathrm{T}$ sections, the shear stresses concentrate in the upper part and around the web, but they extend also to a certain portion of the flanges, in consistency with the experimentally observed behavior. This 
fact has been also recognized by different researchers [5,7,14-19] which consider that part of the flange width contributes to the shear strength.

a)

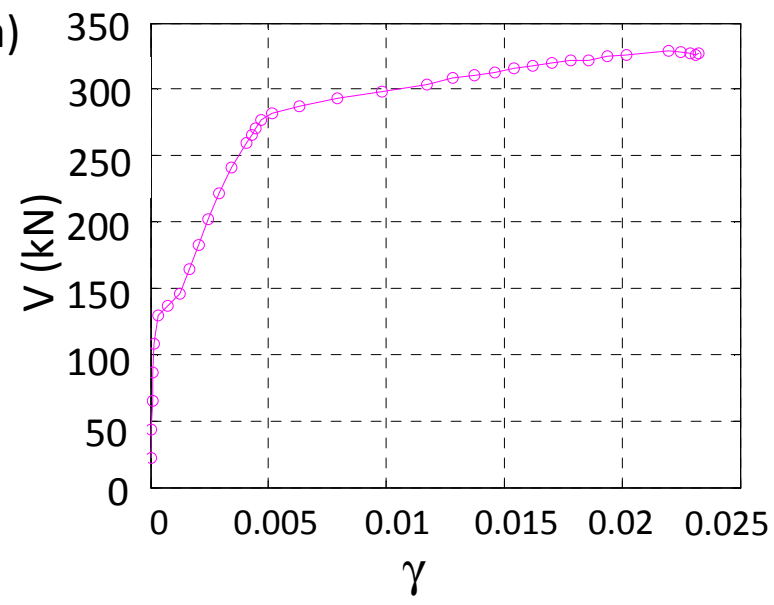

b)
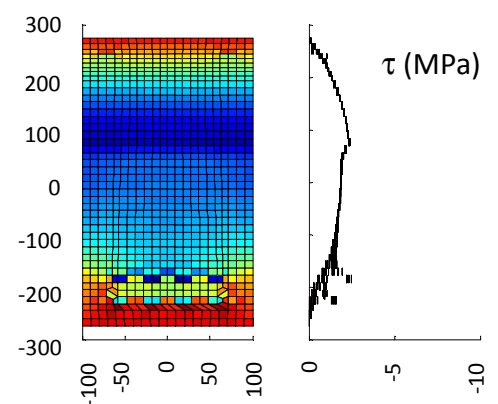

c)

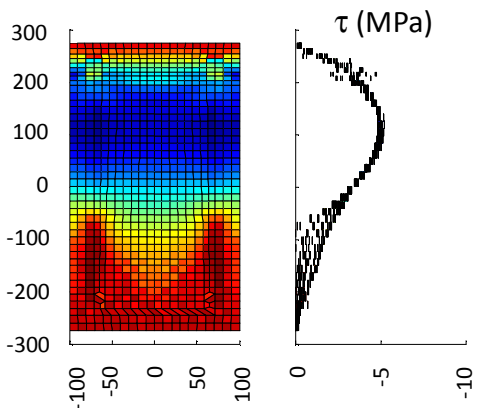

Figure 5. Analysis of a rectangular beam section subjected to an increasing shear forces and bending moments using the coupled model proposed by Bairán and Marí [20]. A) Shear forces vs. shear strains. B) Shear stress distribution at flexural cracking. C) Shear stress distribution after yielding of the longitudinal reinforcement.

In previous works, a shear-flexural strength mechanical model for the design and assessment of reinforced concrete beams was developed by the authors and experimentally verified with large databases of shear tests of steel and FRP reinforced concrete beams with rectangular cross section [21-23]. The model is based on the assumption that, at ULS, shear is resisted mainly by the un-cracked concrete chord, by residual tensile stresses in the closest part of the critical crack, by the longitudinal reinforcement (dowel action) if stirrups are provided and by the stirrups.

According to the observed behavior at failure, the concrete flanges in T-shaped sections may play an important role in the shear strength, which can be quantified by this model. Therefore, in this paper, the previously developed model is extended to beams with $\mathrm{T}$ sections, and general expressions are obtained which can be also applied to beams with rectangular sections, just for the particular case in which $b=b_{w}$. The model is also verified with large databases of RC T-shaped beams with and without stirrups available in the technical literature. 


\section{BRIEF DESCRIPTION OF THE MODEL FOR RECTANGULAR BEAMS}

As widely accepted, the total shear resistance, Eq. (1), is considered to be the addition of the shear resisted by concrete and by the transverse reinforcement $\left(V_{s}\right)$. However, the shear resistant contribution of concrete in this model is explicitly separated into the following components (Figure 6): shear resisted in the un-cracked compression chord $\left(V_{c}\right)$, shear transfer across web cracks $\left(V_{w}\right)$ and the contribution of the longitudinal reinforcement $\left(V_{l}\right)$.

$$
V=V_{c}+V_{w}+V_{l}+V_{s}=f_{c t} \cdot b \cdot d \cdot\left(v_{c}+v_{w}+v_{l}+v_{s}\right)
$$

where $v_{c}, v_{w}, v_{l}$ and $v_{s}$ are the dimensionless values of the shear transfer actions, whose relative contribution to the shear strength varies along the different load stages. As the load increases, the strains at the web, and consequently the crack width, increase and the aggregate interlock decreases; therefore, due to equilibrium, the decrease on aggregate interlock must be balanced by an increase in the shear transferred by the compression concrete chord. The magnitude of each dimensionless contributing component at the imminent failure can be estimated as presented in Table 1. A brief summary of the derivation of each equation presented in Table 1 will be presented later on this paper. It must be highlighted that, in Eq. 1, the individual components have been normalized with respect to the section tensile capacity $f_{c t} \cdot b \cdot d$ but, as will be seen later on this paper, the model assumes that failure is given for a combination of biaxial stresses and, therefore, the proposed formulation could be derived as a function of the tensile concrete strength or the compression concrete strength, without affecting the final result. 

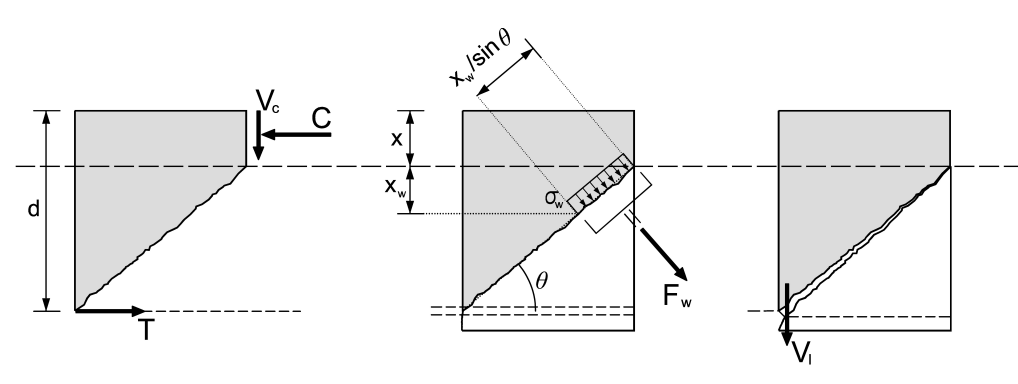

A)

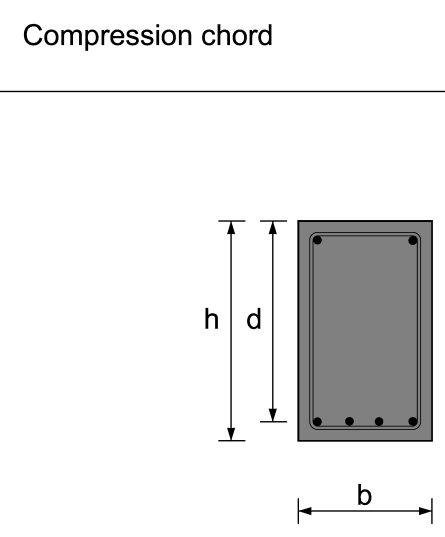

Web crack

Longitudinal reinforcement

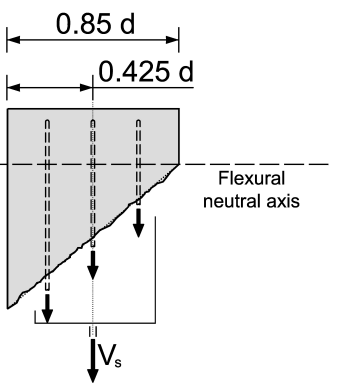

II
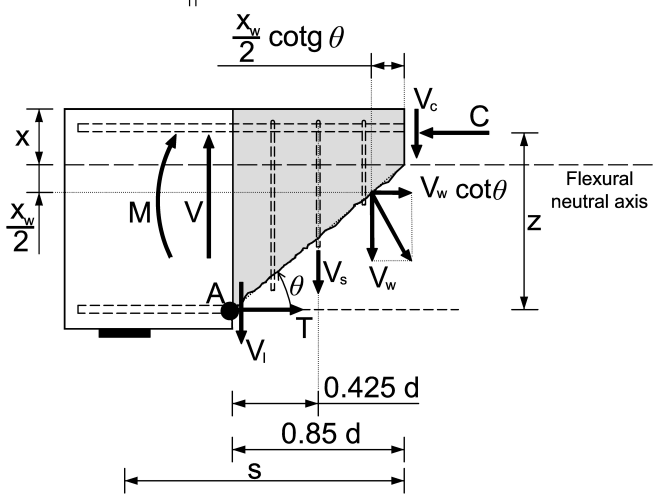

B)

Figure 6. A) Shear transfer mechanisms considered. B) Equilibrium. Adapted from [23].

Table 1. Summary of simplified expressions for rectangular beams of dimensionless shear contributing components [22].

\begin{tabular}{ll}
\hline \multicolumn{1}{c}{ Contributing component } & \multicolumn{1}{c}{ Final simplified dimensionless expressions } \\
\hline Cracked concrete web & $v_{w}=167 \frac{f_{c t}}{E_{c}}\left(1+\frac{2 E_{c} G_{f}}{f_{c t}{ }^{2} d}\right)$ \\
Longitudinal reinforcement & if $v_{s}>0 \rightarrow \mathrm{v}_{\mathrm{l}}=0.23 \frac{\alpha_{e} \cdot \rho}{1-x / d} \approx 0.25 \frac{\mathrm{x}}{\mathrm{d}}-0.05 \geq 0$ \\
Transversal reinforcement & if $v_{s}=0 \rightarrow v_{l}=0$ \\
& $v_{s}=0.85 \rho_{w} \frac{f_{y w}}{f_{c t}}$ \\
Compression chord & $v_{c}=\zeta\left[\left(0.88+0.70 v_{s}\right) \frac{x}{d}+0.02\right]$ \\
& $\zeta=1.2-0.2 \cdot a \geq 0.65$ (a in meters) \\
\hline
\end{tabular}

The following simplifications have been considered during the model formulation:

1. Neutral axis $(x)$ depth and height of the un-cracked concrete zone are treated as equivalent. It is assumed that it can be obtained by standard analysis of cracked reinforced concrete sections under pure flexure (Eq. 7).

$$
\xi=\frac{x}{d}=\alpha_{e} \rho\left(-1+\sqrt{1+\frac{2}{\alpha_{e} \rho}}\right)
$$


where $\alpha_{e}=E_{s} / E_{c}$ is the modular ratio between steel and concrete and $\rho=A_{s} /(b \cdot d)$ is the longitudinal reinforcement ratio, being $b$ the section width.

2. Based on experimental observations made by the authors $[3,21,24,25]$, the horizontal projection of the first branch of the flexural-shear critical crack is considered to be equal to $0.85 d$. This is equivalent to considering that its inclination is approximated as in Eq. (8).

$$
\cot \theta=\frac{0.85}{1-\frac{x}{d}}
$$

In fact, the inclination of the cracks is affected by the longitudinal and transverse reinforcement ratios $\rho$ and $\rho_{w}$, respectively, which influence the strains state. However, as observed by other researchers [26], in general, this influence is moderate, the effect of longitudinal reinforcement ratio being more important [27]. For this reason, only the longitudinal reinforcement has been included, through the neutral axis depth, allowing the model to be direct, non-iterative, both for design and assessment. As a consequence of this assumption, the mean angle of inclination of the critical crack decreases as the longitudinal reinforcement ratio increases, which is consistent with the fact that for the same shear strain, $\gamma$, the longitudinal tensile strain, $\varepsilon_{x}$, is lower.

3. The weakest section in front of a combined shear-bending failure is considered to be placed at the tip of the first branch of the critical crack for beams with constant geometry and reinforcement (Figure 7). Any other section closer to the zero bending moment point has a bigger depth of the compression chord, produced by the inclination of the crack and will resist a higher shear force. Any other section placed between this section and the load application point will have the same depth of the compression chord but will be subjected to higher normal stresses and, therefore, will have a higher shear transfer capacity. The critical crack (Figure 7) is assumed to start where the bending moment diagram at failure reaches the cracking moment of the section, $s_{c r}=M_{c r} V_{u}$, which is a conservative assumption. A similar approach has also been used in other shear models $[28,29]$. 
4. Horizontal normal stresses $\left(\sigma_{x}\right)$ are computed according to linear theory as longitudinal reinforcement is generally in elastic regime in the critical section. Figure 8 presents the different stress distributions assumed, in a simplify manner, at the compression chord in the critical section (section B in Figure 7). When setting the equilibrium of internal forces in the portion of beam of Figure $6 \mathrm{~B}$, the bending moment and the shear force can be considered applied indistinctly at the crack initiation section (as indicated in Figure 6) or at the critical section (crack tip). Let's consider $V_{i}$ and $M_{i}$ the internal forces at the crack initiation section, and $V_{t}$ and $M_{t}$ the internal forces at the crack tip section. If it is taken into account that $V_{t}=V_{i}$ and that $M_{t}=M_{i}+V i \cdot 0.85 d$, the same equilibrium equations and the same values are obtained for the compression at the concrete chord, $C$, and for the tensile force $T$. Moreover, when stirrups are anchored in the compression zone, they collaborate in the strength of the compression chord by producing a confining vertical compression $\left(\sigma_{y}\right)$ at depth larger than the concrete cover ( $\left.d^{\prime}\right)$.

5. Resistance of compression chord is governed by Kupfer's biaxial failure envelope. It is considered that failure occurs when the principal stresses reach the Kupfer's compression-tension branch of the failure surface [30].

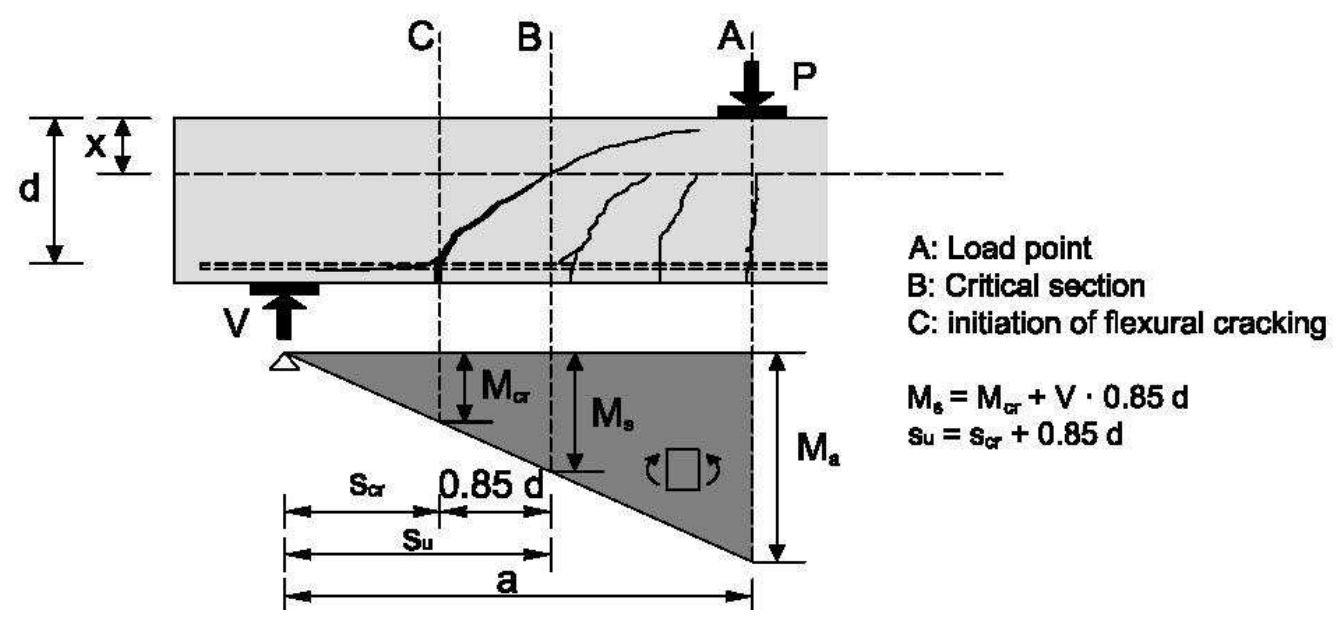

Figure 7. Position of the shear critical section in the beam. Adapted from [22]. 


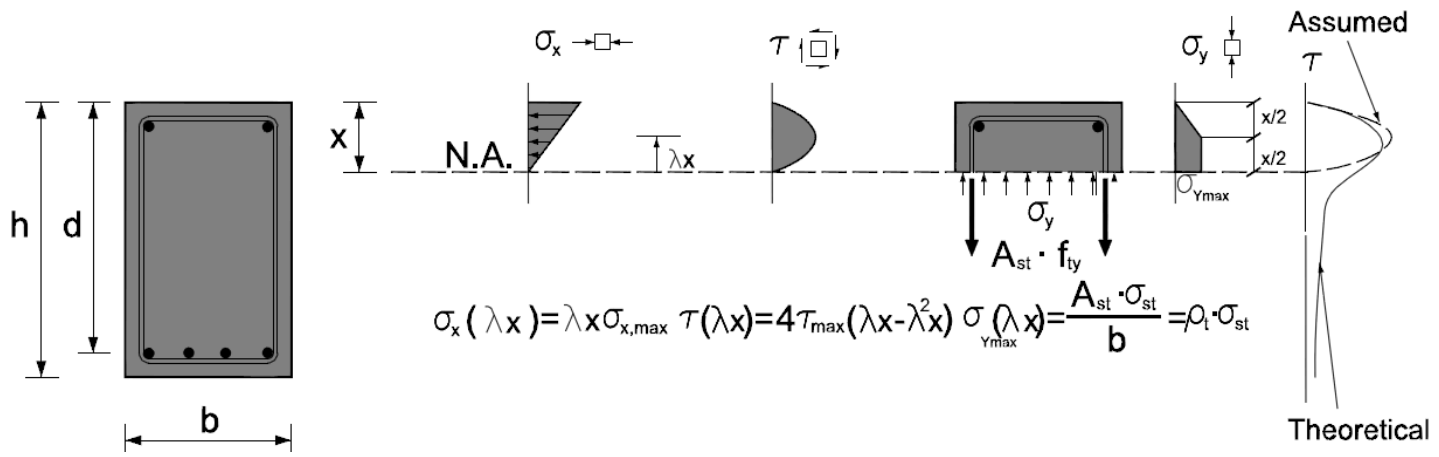

Figure 8. Considered distributions of stresses at the un-cracked concrete chord. Adapted from [22].

The tensile concrete strength, $f_{c t}$, is evaluated in the application of the previous equations by using EC-2 equations, but limiting the concrete compressive strength to 60 $\mathrm{MPa}$, as has been previously shown that the shear strength of reinforced concrete beams without stirrups does not increase significantly for high-strength concrete beams due to the fracture of the aggregates [24,25]. The concrete modulus of elasticity has also been evaluated according to EC-2, limiting also $\mathrm{f}_{\mathrm{ck}}$ to $60 \mathrm{MPa}$ for its calculation. $G_{f}$ in Eq. (2) is the concrete fracture energy whose recommended value is $\mathrm{G}_{\mathrm{f}}=0.028 \mathrm{f}_{\mathrm{cm}}^{0.18} \mathrm{~d}_{\mathrm{g}}^{0.32}$ [22]. In fact, the fracture energy, $G_{f}$, depends primarily on the water-cement ratio, the aggregate type, the maximum aggregate size, the age of concrete and the curing conditions. According to the Model Code 2010 [31], $G_{f}$ can be expressed as a function which depends only on the concrete mean compressive strength, $f_{c m}$, but Wittmann [32] proposed an expression which only depends on the maximum aggregate size $d_{\max }$. In this paper, the expression recommended depends on the two parameters, $f_{c m}$ and $d_{\max }$. The correlation of this expression with experimental results may be seen in [22].

The complete derivation of the dimensionless shear contributing components (Eqs. 2-6) may be found elsewhere [22,23]. Shear resistance of cracked concrete in the web (Eq. 2) is considered as the residual tensile stress of cracked concrete transferred in the closest part of the crack with a depth equal to $x_{w}$ (see Figure 6A). The contribution of longitudinal reinforcement, or dowel action, is taken into account only when transversal reinforcement exists, Eq. (3a), being negligible when there are no stirrups, Eq. (3b). Stirrups provide a constraint to the vertical movement of the longitudinal bars, enabling them to transfer a certain shear. In order to evaluate such shear force, it was considered that the longitudinal bars are doubly fixed at the two stirrups adjacent to the crack initiation, and subjected to bending due to a relative imposed displacement between those points. This vertical relative displacement is caused by the critical crack opening 
and the shear deformation of the compression chord. The contribution of transversal reinforcement, Eq. (4) of Table 1, is taken as the integration of the stresses cut by the inclined crack up to a height of $(d-x)$, see Figure 6, and assuming that transversal reinforcement is yielded along the total crack height.

Finally, the shear capacity of the compression chord (Eq. 5) is evaluated assuming that failure occurs when the first fiber in the compression chord reaches the Kupfer's failure envelope. By means of a Mohr's circle analysis, Eq. (9) can be derived where $\sigma_{x}$ is the normal stress in the most critical fiber (Figure 8), located at position $\lambda \cdot x$ from the bottom of the neutral axis. $K_{\lambda}$ is a parameter relating the mean shear stress in the compression chord with stress in the critical fiber; therefore, it depends on the shape of the distribution of shear stresses in the compression chord, and the critical fiber.

$$
V_{c}=\int_{0}^{x} \tau(y) \cdot b \cdot d y=\frac{\tau_{\lambda} \cdot b \cdot x}{6 \cdot \lambda \cdot(1-\lambda)}=K_{\lambda} \cdot b \cdot x \cdot \sigma_{1} \sqrt{1-\frac{\left(\sigma_{x}+\sigma_{y}\right)}{\sigma_{1}}+\frac{\left(\sigma_{x} \sigma_{y}\right)}{\sigma_{1}{ }^{2}}}
$$

In order to obtain the beam strength, the shear capacity must be calculated at the critical section, placed at the tip of the first branch of the critical shear crack. Equilibrium between the internal forces $(V, M)$ and the stress resultants (Figure 6B) at the concrete chord $\left(C, V_{c}\right)$, along the crack $\left(V_{w}\right)$, at the stirrups $\left(V_{s}\right)$ and at the longitudinal reinforcement $\left(T, V_{l}\right)$ is taken in the portion indicated by Figure 6B. Equilibrium of moments is taken with respect to the point A (Figure 6B), where the critical crack reaches the reinforcement.

$$
\begin{gathered}
C=T+V_{w} \cdot \tan \theta \\
V=V_{c}+V_{w}+V_{l}+V_{s} \\
C \cdot z=M+V_{c} \cdot 0.85 \cdot d+V_{w} \cdot z_{w}+0.5 \cdot V_{s} \cdot 0.85 \cdot d
\end{gathered}
$$

where $V_{w}$ is the vertical component of the tensile force transferred along the crack, and $z_{w}$ is its lever arm with respect to point A (Figure 6B):

$$
z_{w}=\frac{0.85 \cdot d-0.5 \cdot x_{w} \cdot \cot \theta}{\cos ^{2} \theta}
$$


The normal stress $\sigma_{x}$ in the most critical fiber $(\mathrm{y}=\lambda \mathrm{x})$ of the compression chord can be expressed as function of the internal forces by means of a classical flexural analysis of a cracked section. In dimensionless terms it may be expressed as in Eq. (14):

$$
\frac{\sigma_{x}}{f_{c t}}=\frac{2 \cdot \lambda \cdot\left(\mu_{c r}+0.85 \cdot v_{c}+v_{w} \cdot z_{w}+v_{s} \cdot 0.425\right)}{\xi \cdot\left(1-\frac{\xi}{3}\right)}
$$

Where $\mu_{c r}$ is the dimensionless moment (Eq. 15) existing at failure in the section where the critical crack initiates, which is the cracking moment $M_{c r}$ in the proposed model, whose value for rectangular sections is:

$$
\mu_{c r}=\frac{M_{c r}}{f_{c t} \cdot b \cdot d^{2}}=\frac{b \cdot h^{2} \cdot f_{c t}}{6 \cdot f_{c t} \cdot b \cdot d^{2}}=\frac{1}{6} \cdot\left(\frac{h}{d}\right)^{2} \approx 0.2
$$

and $\xi_{w}=x_{w} / d, x_{w}$ is the depth of the tension zone where residual tensile stresses are transferred across the crack.

After a numerical parametric study, it was observed that the position of the critical fiber can be reasonably considered constant, for reinforced elements, and approximately equal to $\lambda \approx 0.425$.

Further, by relating the vertical confining stress $\left(\sigma_{y}\right)$ with the capacity of the transversal reinforcement $\left(v_{s}\right)$, Eq. 16 is derived for the shear capacity of the compression chord, where $R_{t}=\sigma_{l} / f_{c t}$, is a reduction factor of the tensile stress due to the biaxial stress state.

$$
v_{c}=R_{t} K_{\lambda} \zeta \xi \sqrt{1-\frac{2 \cdot \lambda\left(\mu_{c r}+0.85 v_{c}+v_{w} z_{w}+0.425 v_{s}\right)}{\xi\left(1-\frac{\xi}{3}\right) R_{t}}\left(\frac{v_{s}}{0.85 R_{t}}-1\right)-\frac{v_{s}}{0.85 R_{t}}}
$$

Where $\zeta$ is the size effect parameter for the compression chord (Eq. 6), which can be assimilated to that of a splitting test, as proposed by Zararis and Papadakis [2]. Equation 16 is a general expression based on a rational mechanical analysis; however, it must be solved iteratively since $R_{t}$ depends on the principal compression stress which is not known "a priori". Nonetheless, it was found that the exact solution of Eq. (16) can be very well approximated by the simplified linear equation presented in Eq. (5) of Table 1 , in which the applied bending moment at the critical crack initiation was conservatively considered as the cracking moment. It is observed that the shear transferred by the un-cracked concrete chord depends linearly on the neutral axis depth, 
as previously obtained in [17] using a similar approach. Since the neutral axis depth depends on the longitudinal reinforcement ratio, $\rho$, and on the modular ratio, $\alpha_{e}=E_{s} / E_{c}$, the higher the longitudinal reinforcement amount, the higher the shear resisted by the concrete chord. In addition, it is observed that $v_{c}$ depends also on the shear carried by the transverse reinforcement, $v_{s}$, as was observed experimentally [24,33].

In the previous model derivation, a constant shear force in the shear span was assumed. In the case of beams subjected to uniformly distributed loads, due to the different shear forces and bending moment distributions with respect to point loads, the model predicts that the critical shear crack will be even closer to the support, as observed in the results of the Stuttgart tests [34]. The concrete chord contribution $V_{c}$ can be similarly derived by including the distributed load in the equilibrium equations as Marí et al. [23] deduced. The reaction should be calculated by adding to the predicted ultimate shear at the critical section, the portion of distributed load in the support neighbourhood who runs directly to the support. In relation to the shear span, $a$, for beams under uniformly distributed loads, the parameter that can be used in the calculation of the size effect, according to Eq. (6), is considered to be equal to $a=L / 4$, being $L$ the span of a simply supported beam or the distance between points with null bending moment.

\section{EXTENSION OF THE SHEAR-FLEXURAL STRENGTH MECHANICAL MODEL FOR T-SHAPED BEAMS}

\subsection{Influence of the T-shape on the shear response}

In order to extend the flexural-shear strength mechanical model to beams with T-shaped sections, the following four aspects must be taken into account:

1) According to numerical analyses performed $[11,12,20]$ only a portion of the flanges closer to the web contributes to resist shear, being this portion approximately equal to $h_{f}$ at each side of the web. The analyses were performed for different structural elements. For example, Figure 9 shows the analysis of the shear stresses in a beam-and-block floor rib [11] by a nonlinear analysis smeared-crack model with rotating-cracks. The model used in this study [20] takes into account warping and distortion of the cross-section in both vertical 
and horizontal directions, hence the spreading of the shear stresses in the compression flange is obtained in terms of the damage state in the different parts of the section. Note also the parts per unit of the total shear transmitted in the area enclosed by a black line presented in the figure (area close to the flangeweb intersection, Figure 9) just before failure. For this particular case, the ratio of shear force carried by the top part of the web and the flange arrives to a value of 0.79 of the applied shear at that moment. Similar analyses have been performed to other T-shaped beams, arriving to similar results. Consequently, in this work a shear effective flange width $b_{v}$ is defined as indicated in Eq. (17) and in Figure 10.

$$
b_{v}=b_{w}+2 h_{f} \leq b
$$

Eq. (17) is coincident with that proposed by Placas and Regan [7] and Zsutty [10]. However, Moayer and Regan [35] reduced the influence of the flanges considering an effective width equal to $b_{w}+1.5 h_{f}$, although Moayer and Regan considered the influence of all the flange depth, $h_{f}$, and not only until the neutral axis depth, $x$, as in this proposal. Wolf and Frosch [19] proposed an effective flange width equal to $b_{w}+h_{f}$.
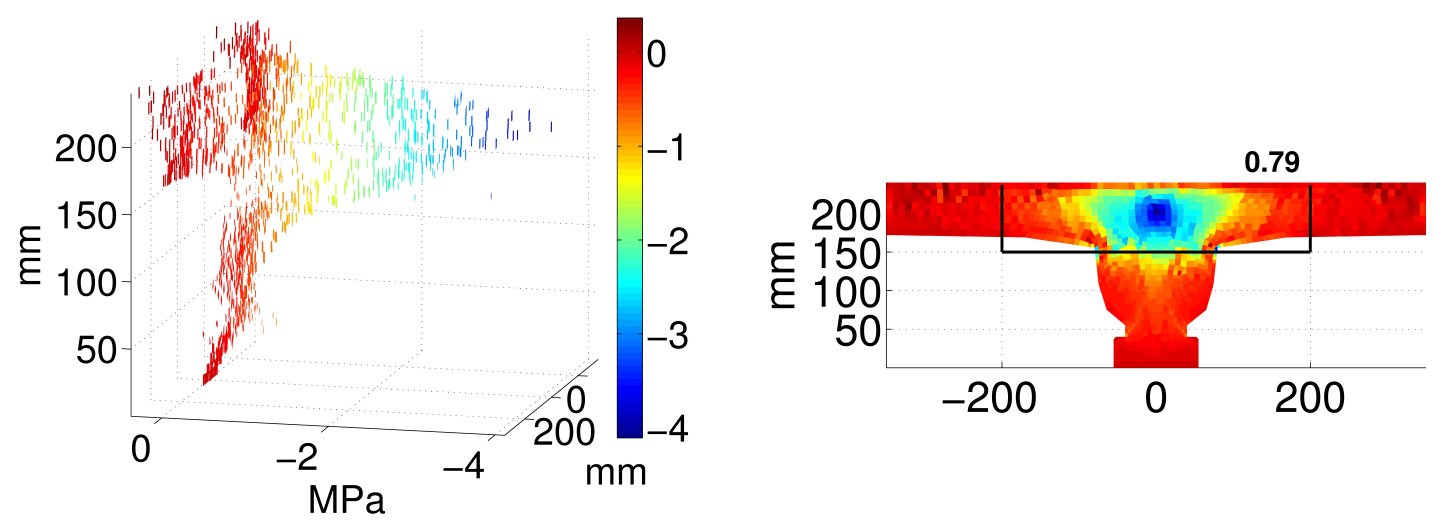

Figure 9. Shear stresses at high load levels in a T-shaped section. Adapted from [11]. 


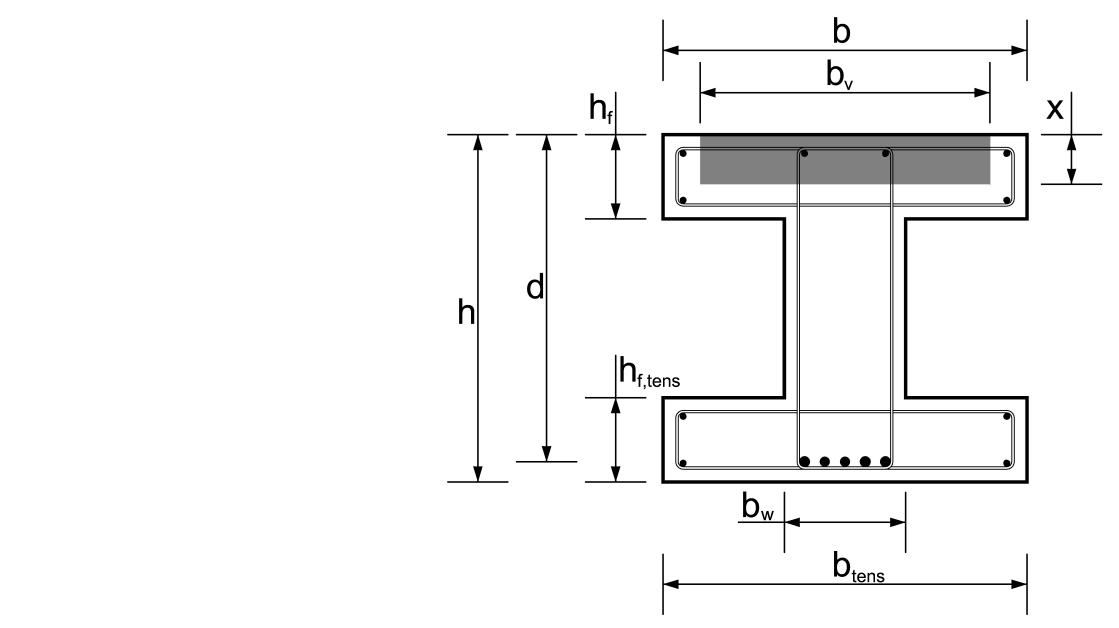

Figure 10. Effective width in a I-shaped section.

2) The cracking moment of a $\mathrm{T}$ section (or I section) is different to that of a rectangular section. This fact affects the position where the critical crack initiates, the position of the critical section and the level of normal stresses at the compression concrete chord. The ratio between the cracking moments of the $\mathrm{T}$ or I section $\left(\mathrm{M}_{\mathrm{cr}, \mathrm{T}}\right)$ and that of a rectangular reference section of the same height and $b=b_{w},\left(M_{c r, R w}\right)$, is called $K_{c r}=M_{c r, T} / M_{c r, R w}$, and can be obtained analytically. A very good approximation can be also obtained by Eq. (18).

$$
K_{c r}=\frac{M_{c r, T}}{M_{c r, R w}} \simeq 0.9+0.1 \frac{b}{b_{w}}+2.5 \frac{h_{f, t e n s}}{h}\left(\frac{b_{\text {tens }}}{b_{w}}-1\right)
$$

It is also possible to define a coefficient $K_{T}$ as a product of $K_{c r}$ by the ratio $b_{w} / b$. This coefficient will be useful in the derivation of the contribution of the compression concrete chord for T or I-shaped beams, and it is given by Eq. (19). Note that in Eq. 19 the width $b$ is used, and not $b_{v}$, as the cracking moment is related to the flexural behavior and not to the shear stresses.

$$
K_{T}=\frac{M_{c r, T}}{M_{c r, R w}} \frac{b_{w}}{b} \simeq 0.1+0.9 \frac{b_{w}}{b}+2.5 \frac{h_{f, \text { tens }}}{h}\left(\frac{b_{\text {tens }}-b_{w}}{b}\right)
$$

3) In a cracked $\mathrm{T}$ beam, in the case that the neutral axis depth, $x$, is placed inside the concrete chord $\left(x \leq h_{f}\right)$, the width of the concrete compression block is equal to the flexural effective width of the flanges, $b$. The neutral axis depth becomes, therefore, smaller than that of the reference rectangular section of $b=b_{w}$. The 
following equation provides the limit condition for the location of the neutral axis depth with respect to the flanges depth, $h_{f}$ :

$$
x \leq h_{f} \quad \text { if } \quad \alpha_{e} \rho \leq \frac{1}{2} \frac{\delta^{2}}{(1-\delta)} \quad ; \quad \delta=\frac{h_{f}}{d} \quad ; \quad \rho=\frac{A_{s}}{b \cdot d}
$$

In that case, Eq. (7) which corresponds to a rectangular section of effective depth, $d$, and width, $b$, may be used to obtain the neutral axis depth (see Figures 11 and 12A). Therefore, in a T-sheap beam the neutral axis depth will be lower than that of a similar rectangular beam with a constant width equal to that of the web of the T beam, $b_{w}$, and the cracks will be more vertical as predicted by Eq. (8). This fact was recognized by Leonhardt in 1965 [36].

If Eq. (20) is not satisfied, the neutral axis depth will be $x>h_{f}$ and it can be calculated by solving Eq. (21), derived by setting the equilibrium of horizontal forces in the section, accounting for the two different widths of the section, see Figure 12B.

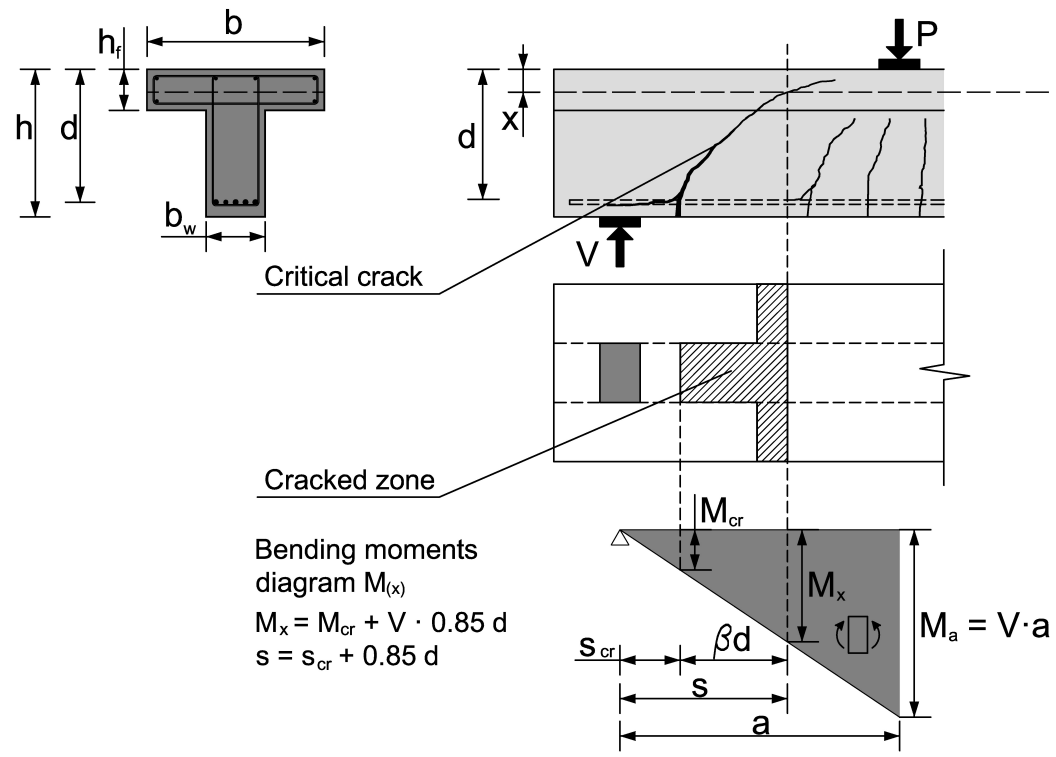

Figure 11. Scheme of cracking in a beam with T section $\left(x \leq h_{f}\right)$.
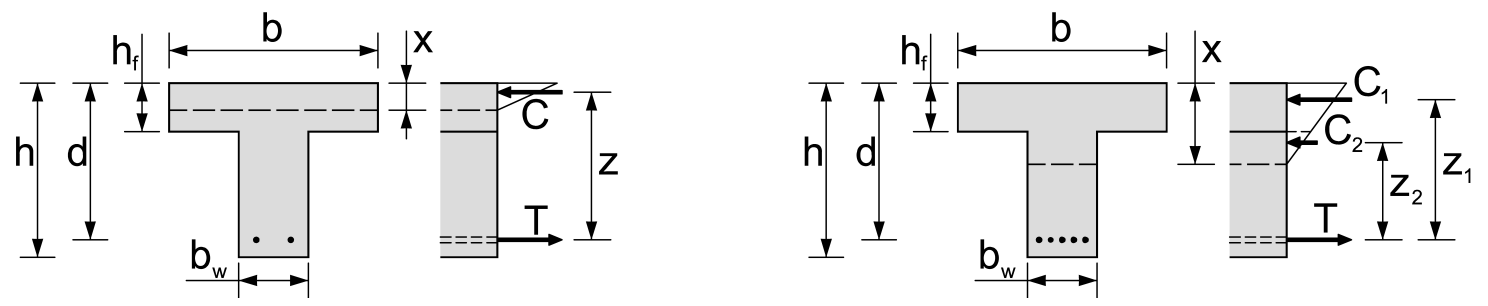

Figure 12. Neutral axis depth in a T section. A) $x \leq h_{f}$ B) $x>h_{f}$. 


$$
\xi^{2}+2 \xi\left[\delta(\eta-1)+\alpha_{e} \rho \eta\right]-\left[\delta^{2}(\eta-1)+2 \alpha_{e} \rho \eta\right]=0
$$

Where $\eta=b / b_{w}$ and the rest of parameters have been previously defined. The exact solution to Eq. (21) is presented in Appendix A.

4) When $x<h_{f}$, the crack may penetrate into the flanges, assuming a more horizontal path than in the web (Fig. 3C), due to the difference in the ratio between the normal and the shear stresses generated by the change of width, see Figure 13. Therefore, the horizontal projection of the critical crack, $\beta d$, is higher than in the reference rectangular section. This fact has three consequences:

a. It affects the position of the critical section, which is placed slightly farther from the support and, therefore, subjected to higher compressive stresses in the un-cracked concrete chord, thus increasing its shear transfer capacity. Nevertheless, the increment of shear capacity due to the slight change of position of the critical section is very small.

b. The transverse reinforcement contribution to the shear strength, $V_{s}$, increases because the horizontal projection of the crack increases. This fact, which only affects beams with transverse reinforcement in which the neutral axis depth is smaller than the flanges depth, may increase the stirrups contribution to the shear strength.

c. The relative vertical displacement between the crack surfaces is higher because the global inclination of the critical crack is higher, see Figure 13, affecting the dowel action. This effect is small in the global shear strength and it is neglected in the proposed equations. Additionally, for the two expressions given in Eq. 3a for the longitudinal reinforcement dimensionless shear contribution, only the first one will be considered, as the approximation given by $0.25 x / d-0.05$ is only valid for rectangular sections.

d. The residual tensile stresses transferred in the closest part of the crack, $V_{w}$, may be located in two different domains: the flanges and the web. As this transfer action is relatively small compared to the compression chord transfer capacity and for simplicity, only the residual stresses included in 
$b_{w}$ will be accounted for in the proposed model, which is a conservative assumption. For this reason, Eq. (2) valid for rectangular sections must be normalized taken into account only $b_{w}$.

In order to evaluate the effect in $V_{s}$, it is essential to obtain the inclination of the crack in the flanges and the global angle of inclination. From Figure 13, the following ratio between the global crack angle, $\theta$, and the inclinations of the web crack, $\theta_{w}$, and the flange crack, $\theta_{f}$, is obtained from geometrical considerations (Eq. 22). The value of $\cot \theta_{w}$ is directly obtained by Eq. (8).

$$
\cot \theta=\frac{\left(d-h_{f}\right) \cot \theta_{w}+\left(h_{f}-x\right) \cot \theta_{f}}{(d-x)}
$$

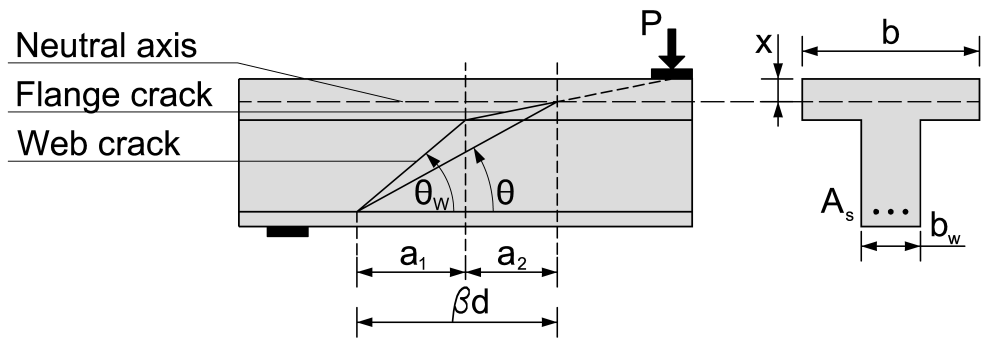

Figure 13. Inclined crack with two branches in beams with T section.

Assuming that the ratio between the angle of inclination of the crack in the web and in the flanges is similar to the ratio between the angle of inclination of the tensile principal stress in the crack and in the flange, this ratio can be obtained, in an approximate manner, from the Mohr's circle of stresses. See Appendix B for the complete derivation. In summary, Eq. (22) can be rewritten as Eq. (23):

$$
\begin{gathered}
\cot \theta=\cot \theta_{w} \frac{\left(d-h_{f}\right)+\left(h_{f}-x\right) R_{\theta}}{(d-x)}=\cot \theta_{w} \frac{\left(d-h_{f}\right)+\left(h_{f}-x\right) \frac{b_{v}}{b_{w}}}{d-x}=\frac{0.85}{1-\frac{x}{d}} K_{\theta} \\
K_{\theta}=\frac{\left(d-h_{f}\right)+\left(h_{f}-x\right) \frac{b_{v}}{b_{w}}}{d-x}
\end{gathered}
$$

and the horizontal projection of the crack will be:

$$
\beta d=0.85 \cdot K_{\theta} \cdot d
$$


In any case, after the first branch of the shear critical crack reaches the compression flanges, a higher load is necessary to crack the compression flange due to its higher width. Nevertheless, sometimes, while the load increases, the crack propagates horizontally along the web-flanges joint due to the longitudinal shear stresses at that joint produced by the shear lag. This effect is conservatively not taken into account in this model.

\subsection{Compression chord contribution to the shear strength, $V_{c}$, in T-shaped beams}

In order to obtain the beam shear capacity, the non-dimensional compression chord contribution to the shear strength, $v_{c}$ given by Eq. (5), must be modified to take into account the influence of the T-shape, according to the above considerations. Related to the position of the neutral axis depth, the following situations can take place:

\subsubsection{Neutral axis inside the compression flange $\left(x \leq h_{f}\right)$}

The formulation developed for rectangular sections is still valid for this case, with small modifications. When calculating the normal stresses due to bending, Eq. (14), the neutral axis depth must be obtained with a reinforcement ratio $\rho=A_{s} /(b \cdot d)$ relative to the compression flange flexural effective width, $b$. In addition, the cracking moment of the T section, $M_{c r, T}$, must be used. Then, Eq. (14) can be rewritten, as in Eq. (26):

$$
\frac{\sigma_{x}}{f_{c t}}=\frac{2 \lambda\left(\frac{M_{c r, T}}{f_{c t} b d^{2}}+\beta \cdot v_{c}+v_{w} \frac{\left(\beta-0.5 \xi_{w} \cot \theta\right)}{\cos ^{2} \theta}+v_{s} 0.5 \beta\right)}{\xi \cdot\left(1-\frac{\xi}{3}\right)}=\frac{2 \lambda\left(0.2 K_{T}+\beta \cdot v_{c}+v_{w} \frac{\left(\beta-0.5 \xi_{w} \cot \theta\right)}{\cos ^{2} \theta}+v_{s} 0.5 \beta\right)}{\xi \cdot\left(1-\frac{\xi}{3}\right)}
$$

Since the neutral axis lies in the flanges, not the whole flanges width but the shear effective flange width $b_{v}$ must be used when integrating the shear stresses. Then Eq. (16) becomes:

$$
v_{c}=R_{t} K_{\lambda} \zeta \xi \frac{b_{v}}{b} \sqrt{1-\frac{2 \cdot \lambda\left(0.2 K_{T}+\beta v_{c}+v_{w} z_{w}+0.5 \cdot \beta v_{s}\right)}{\xi\left(1-\frac{\xi}{3}\right) R_{t}}\left(\frac{v_{s}}{\beta R_{t}}-1\right)-\frac{v_{s}}{\beta R_{t}}}
$$




\subsubsection{Neutral axis in the web $\left(x>h_{f}\right)$}

In order to obtain $V_{c}$, Equation (9) must be integrated in two domains, corresponding to the flanges $\left(x<h_{f}, \quad b=b_{v}\right)$ and to the compressed part of the web $\left(x>h_{f}, b=b_{w}\right)$, and becomes:

$$
V_{c}=\int_{0}^{h_{f}} \tau(y) \cdot b_{v} \cdot d y+\int_{h_{f}}^{x} \tau(y) \cdot b_{w} \cdot d y=\frac{\tau_{\lambda} \cdot b_{v, e f f} \cdot x}{6 \cdot \lambda \cdot(1-\lambda)}
$$

where

$$
b_{v, \text { eff }}=b_{v}\left[v^{2}(3-2 v)+\frac{b_{w}}{b_{v}}\left(1-3 v^{2}+2 v^{3}\right)\right] \quad ; \quad v=\frac{h_{f}}{x}
$$

Then, Eq. (27) is also valid in the case $x>h_{f}$ substituting $b_{v}$ by $b_{v, \text { eff. Eq (27) has been }}$ solved for $x / d$ adopting different values of $b / b_{w}$, (or $K_{T}$ ), and different transverse reinforcement shear capacities $v_{s}$. Figure 14 shows the solutions obtained for $v_{s}=0$ and $0.25, b / b_{w}=1,3$ and 5 and $h_{f} / d=0.125$.

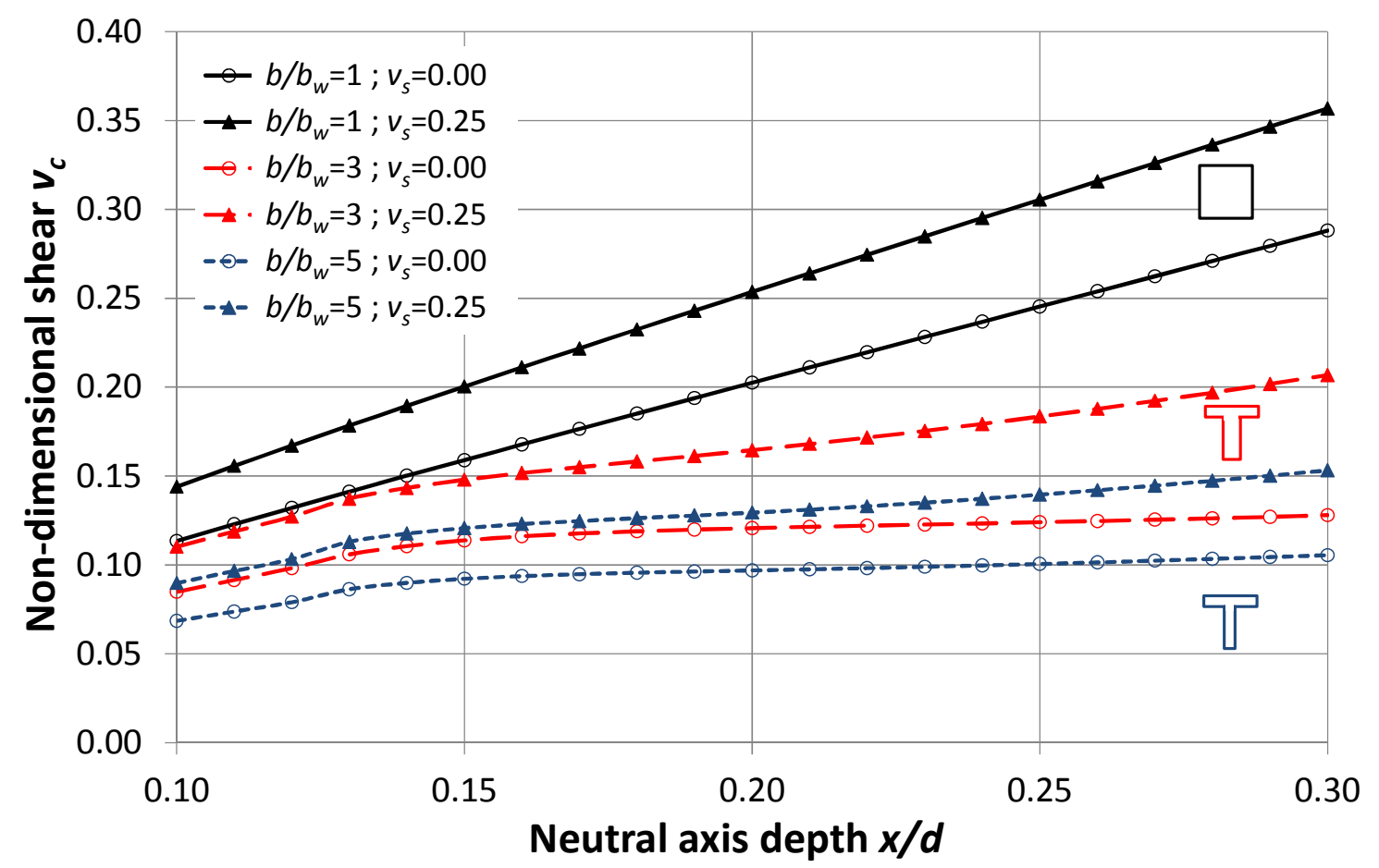

Figure 14. Concrete chord contribution to shear strength for different $\mathrm{T}$ or rectangular beams.

It can be observed in Figure 14 that in T beams $\left(b>b_{w}\right)$, when the neutral axis depth is higher than the flange depth $\left(x / d>h_{f} / d\right)$, the slope of $v_{c}$ diminishes, since the web width is lower than the flange width, and $b_{v, \text { eff }}$ diminishes as $x / d$ increases. 
Eq. (30) can be used, that conservatively fits quite well the actual results of Eq. (27) valid for any value of the neutral axis depth:

$$
v_{c}=\zeta\left[\left(0.70+0.18 K_{T}+\left(0.20+0.50 \frac{b}{b_{w}}\right) v_{s}\right) \frac{x}{d}+0.02 K_{T}\right] \frac{b_{v, e f f}}{b}
$$

For a rectangular section, in which $b=b_{v}=b_{v, \text { eff }}=b_{w}$ and $K_{T}=1$, Eq. (30) results identical to Eq. (5).

\subsection{Maximum shear strength due to strut crushing}

The web width in $\mathrm{T}$ beams, $b_{w}$, may be relatively thin, and the beam failure may be governed by the concrete struts. This proposal adopts the same formulation of the current EC-2 but considering the angle of the compression strut given by Eq. (8).

\section{SUMMARY OF SHEAR MODEL FOR RECTANGULAR AND T-BEAMS}

The shear strength of rectangular and $\mathrm{T}$ beams is given by Eqs. (31-32):

$$
\begin{gathered}
V=V_{c}+V_{w}+V_{l}+V_{s}=f_{c t} \cdot b \cdot d \cdot\left(v_{c}+v_{w}+v_{l}+v_{s}\right) \leq V_{R d, \text { max }} \\
V_{R d, \text { max }}=\alpha_{c w} b_{w} d v_{1} \frac{f_{c k}}{\cot \theta+\tan \theta}
\end{gathered}
$$

where $v_{c}, v_{w}, v_{l}$ and $v_{s}$ are presented in Table 2. The value of the angle of inclination of the struts, $\theta$, may be obtained from Eq. (23); the size effect term, $\zeta$, is given by Eq. (6); $K_{T}$ is defined by Eq. (19) and $K_{\theta}$ by Eq. (24). The parameters $\alpha_{c w}$ and $v_{l}$ are given in the current EC-2 [37]. The effective width for shear strength calculation, $b_{v, \text { eff, }}$ is calculated as follows:

- If $x \leq h_{f}, b_{v, e f f}=b_{v}=b_{w}+2 h_{f} \leq b$

- If $x>h_{f}$, use Eq. (29). 
Table 2. Summary of simplified expressions for rectangular or $\mathrm{T}$ beams of dimensionless shear contributing components

\begin{tabular}{ll}
\hline Contributing component & \multicolumn{1}{c}{ Final simplified dimensionless expressions } \\
\hline Cracked concrete web & $v_{w}=167 \frac{f_{c t}}{E_{c}}\left(1+\frac{2 E_{c} G_{f}}{f_{c t}^{2} d}\right) \frac{b_{w}}{b}$ \\
Longitudinal reinforcement & if $v_{s}>0 \rightarrow v_{l}=0.23 \frac{\alpha_{e} \cdot \rho}{1-x / d}$ \\
& if $v_{s}=0 \rightarrow v_{l}=0$ \\
Transversal reinforcement & $v_{s}=0.85 K_{\theta} \rho_{w} \frac{f_{y w}}{f_{c t}}$ \\
Compression chord & $v_{c}=\zeta\left[\left(0.70+0.18 K_{T}+\left(0.20+0.50 \frac{b}{b_{w}}\right) v_{s}\right) \frac{x}{d}+0.02 K_{T}\right] \frac{b_{v, e f f}}{b}$
\end{tabular}

For design purposes it is recommended to consider $K_{\theta}$ equal to 1.0 which is a conservative assumption. This value will be considered in this paper from now on. Considering $V_{E d}$ the design value of the applied shear force, and $v_{E d}=V_{E d} /\left(f_{c t} b d\right)$ its dimensionless value, the needed amount of shear reinforcement, $v_{s}$, may be directly obtained from the previous equations, resulting in Eq. (37):

$$
v_{S}=\frac{v_{E d}-\zeta\left[\left(0.70+0.18 K_{T}\right) \frac{x}{d}+0.02 K_{T}\right] \frac{b_{v, \text { eff }}}{b}-v_{w}-v_{l}}{1+\zeta \frac{x}{d}\left(0.20+0.50 \frac{b}{b_{w}}\right) \frac{b_{v, \text { eff }}}{b}}
$$

\section{EXPERIMENTAL VERIFICATION}

\subsection{Database for T-beams without shear reinforcement}

The following references of experimental campaigns on $\mathrm{T}$ beams have been considered: Ferguson and Thompson 1953[4], 24 beams; Al-Alusi 1957[38], 25 beams; Placas and Regan 1971 [7], 7 beams; Kani et al. 1979 [6], 178 beams, only with T section; Taylor et al. 1980 [39],1 beam; and Palaskas et al. 1981 [40], 4 beams. Therefore, 239 beams of the campaigns mentioned above have been reviewed, of which 188 elements have been selected for analysis. The following selection criteria have been used: 1) the beams had a ratio $a / d \geq 2.5$, where $a$ is the shear span and $d$ is the effective depth;2) the beams had a compression flange; and 3) the beams had a shear failure.

\subsection{Database for T-beams (or I-beams) with shear reinforcement database}

The ACI-DafStb Evaluation Database for RC beams with stirrups has been considered for the analysis of T-beams and I-beams with shear reinforcement [41]. Only the beams with $\mathrm{T}$ or I section have been selected, resulting in $70 \mathrm{RC}$ T- or I-beams with stirrups. 


\subsection{Global comparison}

In this paper, three shear design procedures have been used to compare their predictions with the experimental results of the T-shaped reinforced concrete beams with and without stirrups. These procedures are the formulations given in Eurocode 2 [37], ACI 318-11 [42] (simplified equation 11-3 of the ACI Code) and in Model Code 2010 [31]. The equations used for the calculation with the proposal presented in this paper are the equations summarized in Section 4 (Eqs. 31-36), considering $K_{\theta}$ equal to 1.0 as previously commented. All explicit safety factors have been removed from the original formulations. Moreover, the reported mean values of the concrete compressive strength and of the tensile strength of the reinforcing bars have been used. The tensile concrete strength, $f_{c t}$, is evaluated according to EC-2 [37], but limiting the concrete compressive strength to $60 \mathrm{MPa}$, as previously commented. Different remarks on the three code design procedures compared in this paper may be found in a similar study made for rectangular beams [22].

Table 3 presents the comparison of the proposal model and the code formulation with the experimental databases. As can be seen, the proposed equation correlates better with the experimental results that any of the considered code formulations, as it presents the lowest standard deviations and the most accurate predictions for the two considered databases.

Table 3. Verification of different procedures for $\mathrm{T}$ and I beams with and without stirrups

\begin{tabular}{lcccccccc}
\hline & \multicolumn{3}{c}{ 188 beams without stirrups } & \multicolumn{3}{c}{ 70 beams with stirrups } \\
\cline { 2 - 8 } \multicolumn{1}{c}{$V_{\text {tes }} / V_{\text {pred }}$} & EC-2 & ACI & MC10 & Proposal & EC-2 & ACI & MC10 & Proposal \\
& 1.32 & 1.89 & 1.36 & 1.02 & 1.25 & 1.82 & 1.41 & 1.14 \\
Average & 1.21 & 1.72 & 1.32 & 0.98 & 1.27 & 1.76 & 1.37 & 1.15 \\
Median & 0.388 & 0.564 & 0.239 & 0.193 & 0.298 & 0.391 & 0.272 & 0.170 \\
Standard deviation & 29.33 & 29.92 & 17.62 & 19.02 & 23.86 & 21.42 & 19.29 & 14.90 \\
COV $(\%)$ & 0.80 & 0.86 & 0.92 & 0.71 & 0.56 & 0.92 & 0.85 & 0.62 \\
Minimun & 0.94 & 1.28 & 1.05 & 0.79 & 0.71 & 1.33 & 1.11 & 0.87 \\
$\left(\mathrm{~V}_{\text {test }} / \mathrm{V}_{\text {pred }}\right)_{5 \%}$ & 3.00 & 4.25 & 2.44 & 2.12 & 2.00 & 3.12 & 2.38 & 1.53 \\
Maximun & 2.11 & 3.05 & 1.81 & 1.35 & 1.75 & 2.49 & 1.81 & 1.39 \\
$\left(\mathrm{~V}_{\text {test }} / \mathrm{V}_{\text {pred }}\right)_{95 \%}$ & & & & & & & &
\end{tabular}


a)

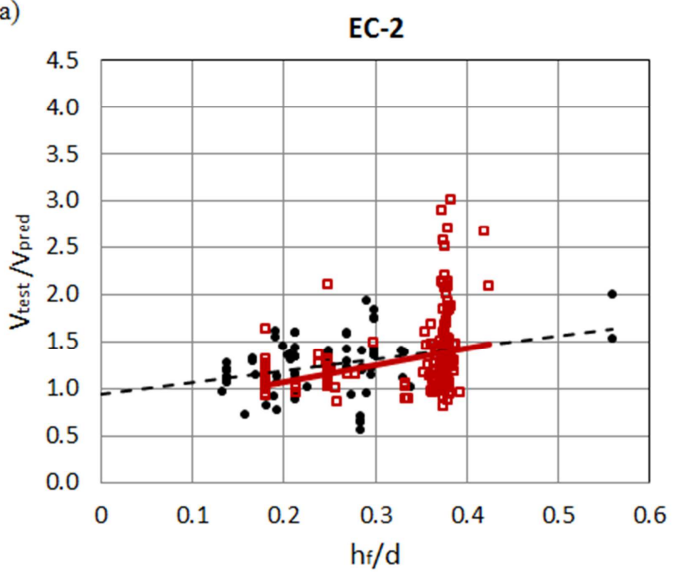

c)

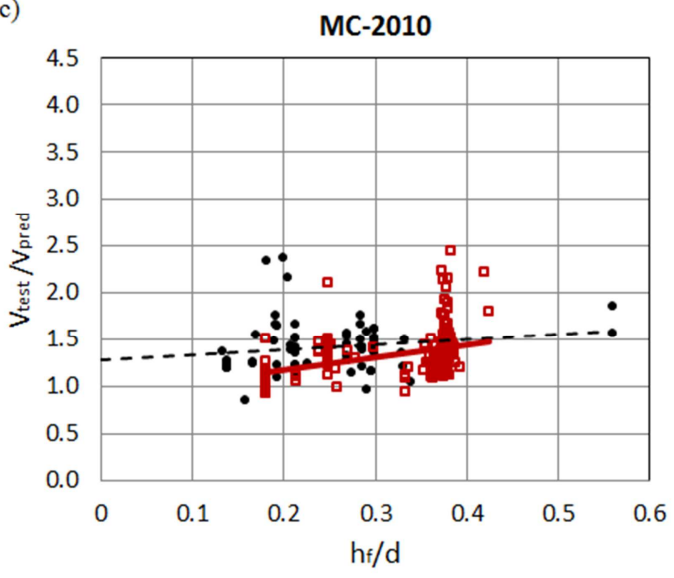

b)

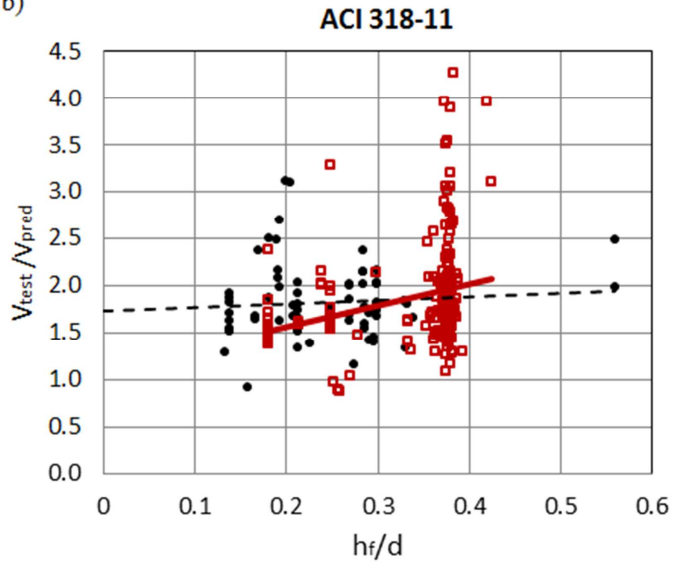

d)

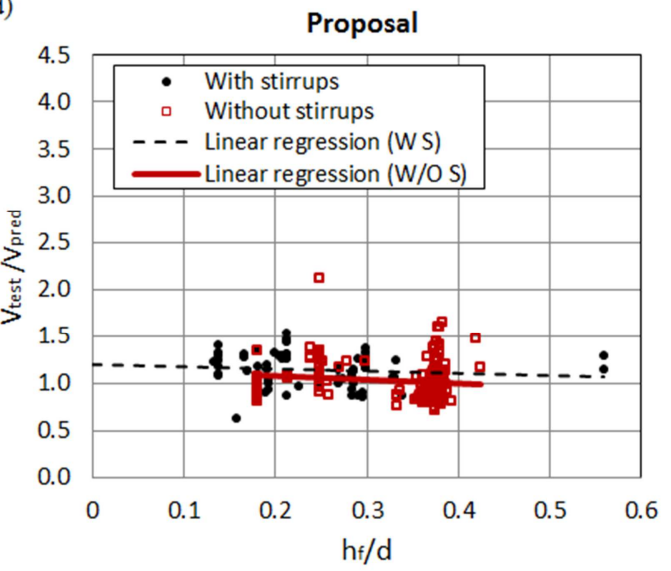

Figure 15. Correlation between the prediction and the experimental results in terms of the ratio of flange to effective depths $\left(h_{f} / d\right)$.

Figure 15 shows the correlation between $V_{\text {test }} / V_{\text {pred }}$ and $h_{f} / d$, where $h_{f}$ is the flange depth and $d$ is the effective depth. Elements with and without shear reinforcement are distinguished, and the linear regression of each group is presented. In Figure 15 can be observed not only the lowest dispersion of the proposal presented in this paper, but also that the higher the ratio $h_{f} / d$ is, the safer the predictions of the codes are. This increment of safety in current code predictions is due to the fact that the codes do not include the effects of flanges, as it is recognized specifically in the Model Code 2010 [31]. Furthermore, the aforementioned tendency is especially significant for beams without stirrups. However, the proposal includes the beneficial effects of the flanges regarding to shear strength, so the linear regressions of the proposal for beams with and without shear reinforcement remain practically horizontal for increasing values of $h_{f} f d$, as is shown in Figure 15.

Kani et al. [6] conducted an extensive campaign in which $178 \mathrm{~T}$-shaped beams without shear reinforcement were tested. 140 of these beams verified the selection criteria 
commented in Section 5.1 and, therefore, they are included in the database of elements without stirrups used in this paper. The studied parameters in this experimental campaign [6] were $\rho, a / d, f_{c}$ and two different values of $b$. The value of the ratio $h_{f} / d$ varied only between 0.37 and 0.42 for these beams, as only small changes in $d$ were done. As none of the compared code formulations take into account properly the different studied parameters for T-shaped beams, a huge scatter can be seen in Figure 15 for this domain $\left(0.37 \leq h_{f} / d \leq 0.42\right)$, specially for ACI 318-11 and EC-2. However, the scatter is much lower for the model proposed in this paper.

An important assumption of the model is that the horizontal projection of the first branch of the flexural-shear critical crack is considered to be equal to $0.85 K_{\theta} d$ (Eq. 25), being $K_{\theta}=1$ for rectangular sections. Figure 16 compares this assumption with the horizontal projection of the actual cracks observed in four beams tested by the authors in two different experimental campaigns $[3,43]$. It can be seen that, for these four tests, the average value is $0.875 K_{\theta} d$, very similar to the assumed value.
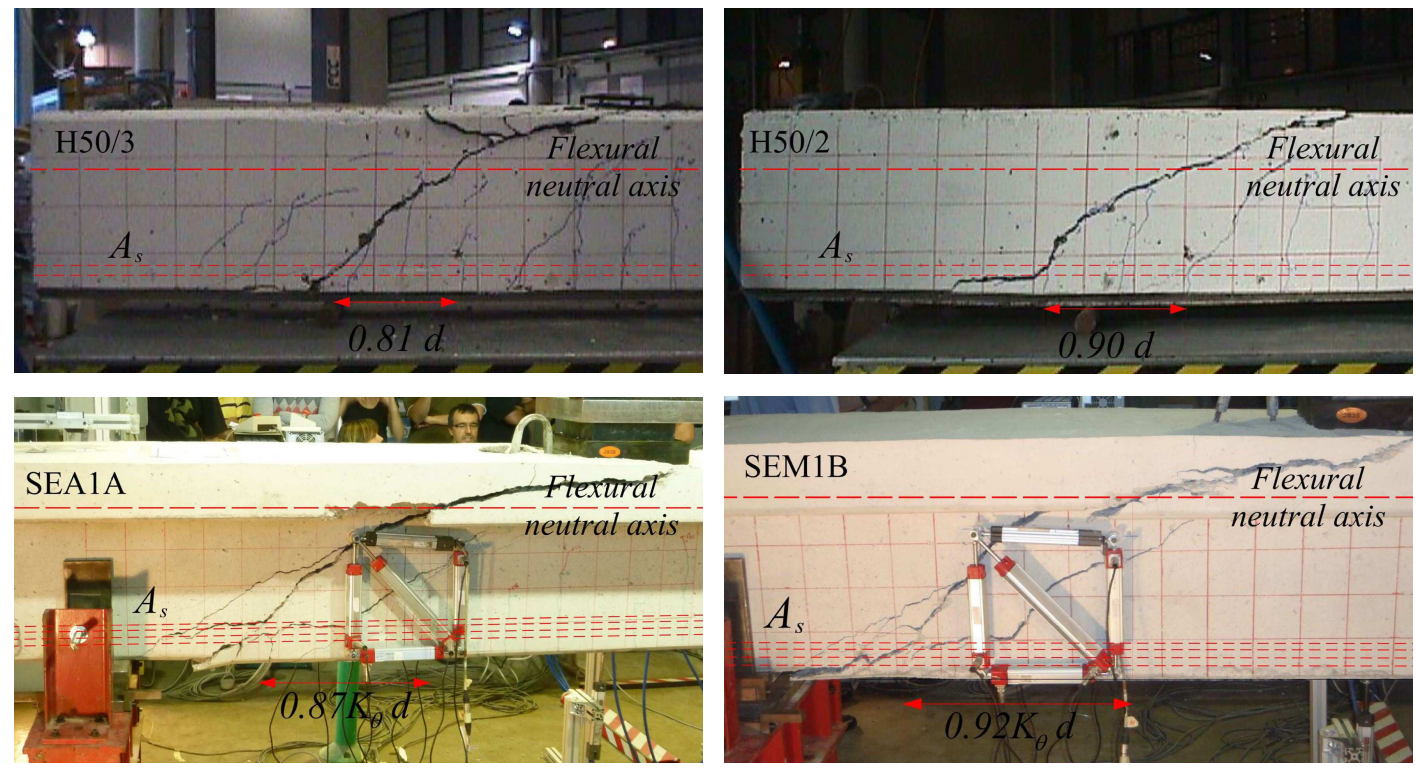

Figure 16: Horizontal projection of the first branch of the flexural-shear critical crack for four beams tested by the authors $[3,43]$.

\section{CONCLUSIONS}

In this paper, a mechanical model previously developed by the authors for the prediction of the shear-flexural strength of slender reinforced concrete beams with rectangular cross section with or without shear reinforcement has been extended to beams with $\mathrm{T}$ 
and I cross sections. For this purpose, the effects of the section shape on the shear transfer actions considered by the model have been identified and incorporated into the corresponding equations. Thus, general expressions both for strength verification and for transverse reinforcement design have been derived, assuming that, when shear failure does not take place by web crushing, failure occurs by propagation of the critical shear crack throughout the compression chord. These expressions are also valid, as particular cases, for beams with inverted $\mathrm{T}$ or rectangular cross sections. The following conclusions can be drawn from the works performed:

1) In the present model it is considered that the critical section is placed at the tip of the shear crack, which develops from a previously formed flexural crack. Therefore, in beams with $\mathrm{T}$ or I sections, the critical section is placed farther from the zero bending moment point than in a beam with a rectangular cross section with the same height and web width $\left(b=b_{w}\right)$, because their cracking moment is higher. This fact is recognized by the model through a theoretically derived shape factor $K_{T}$, affecting the concrete contribution $V_{c}$. The factor $K_{T}$ depends on the cross section dimensions and is equal to 1 for rectangular sections.

2) According to the present model, near the ultimate limit state, a relevant part of shear stresses concentrate at the compression chord. Therefore, when shear failure does not take place by web crushing, the contribution of the compression flanges to the shear strength is relevant and cannot be neglected. Such contribution is taken into account in the model by defining an effective shear width, which depends on the cross section geometry and on the longitudinal reinforcement ratio

3) Due to the existence of compression flanges, the flexural neutral axis depth is smaller than in rectangular beams width the same web width. Therefore, the crack opening and, consequently, the shear transferred along the crack is lower. On the opposite, the dowel action may slightly increase, although the estimated variations of both components are not relevant.

4) When the neutral axis lies into the flanges, both the global inclination and the horizontal projection of the critical crack increase. Consequently, the global 
concrete contribution and the contribution of the web transverse reinforcement increase, resulting in a higher shear resisted.

5) The presence of transverse reinforcement increases the concrete contribution to the shear strength due to two main effects. In one hand the transverse reinforcement introduces vertical confinement stresses in the concrete which enhances its strength, especially in the un-cracked concrete region, i.e. the intersection between the web and the compressed flanges. On the other hand, transverse reinforcement provides a direct contribution to the shear strength and, therefore, an increment of the bending moment acting at the critical section, thus, increasing the shear transfer capacity of the concrete compressed chord.

6) The proposed equations have been checked with experimental results available in the technical literature. In general, very good results have been obtained in terms of mean value $(\mathrm{m})$ and coefficient of variation (cov) of the ratio between the experimental and the predicted results. For the 188 beams without shear reinforcement studied, $\mathrm{m}=1.02$, $\operatorname{cov}=19.02 \%$, while for the 70 beams with shear reinforcement studied, $\mathrm{m}=1.14$ and $\operatorname{cov}=14.90 \%$. These results present more accuracy and less scatter than those obtained with the ACI, Model Code 2010 and Eurocode 2.

7) The proposed simplified equations are direct, (i.e. without need of performing iterations), both for strength verification and for design of the transverse reinforcement. The simplicity, straightforwardness of application and the accuracy of the method make it suitable for daily engineering practice.

\section{ACKNOWLEGMENTS}

The present work has been developed under the framework of research projects BIA2012-36848 and BIA2012-31432, funded by the Spanish Ministry of Economics and the Europeans Funds for Regional Development, and under the financial help of Infraestructures de la Generalitat de Catalunya (ICAT). 


\section{APPENDIX A. Expression for the neutral axis depth for $T$ beams when $x>h_{f}$}

When the neutral axis depth of a $\mathrm{T}$ beam is in the flange $\left(x>h_{f}\right), \mathrm{x} / \mathrm{d}$ may be obtained solving Eq. (21). The exact solution is:

$$
\frac{x}{d}=\left[\delta(\eta-1)+\eta \alpha_{e} \rho_{l}\right]\left[-1+\sqrt{1+\frac{\delta^{2}(\eta-1)+2 \eta \alpha_{e} \rho_{l}}{\left[\delta(\eta-1)+\eta \alpha_{e} \rho_{l}\right]^{2}}}\right]
$$

where $\eta=\frac{b}{b_{w}}, \delta=\frac{h_{f}}{d}, \alpha_{e}=\frac{E_{s}}{E_{c}}$ and $\rho=\frac{A_{s}}{b \cdot d}$.

\section{APPENDIX B. Derivation of $\mathbf{K}_{\theta}$}

The ratio between the angles of inclination of the crack in the web and in the flanges can be obtained, in an approximate manner, from the Mohr's circle of stresses. Let's consider two points inside the section placed where the web intersect the flanges, both at a distance $y=h_{f}$ from the top, but one $\left(\mathrm{P}_{\mathrm{w}}\right)$ inside the web and the other $\left(\mathrm{P}_{\mathrm{f}}\right)$ inside the flanges. When point $\mathrm{P}_{\mathrm{w}}$ cracks, the normal and shear stresses at this point are $\sigma_{x w}$ and $\tau_{w}$, and the principal tensile stress equals the concrete tensile strength, $f_{c t}$.

$$
\sigma_{1, w}=\frac{\sigma_{x w}}{2}+\sqrt{\left(\frac{\sigma_{x w}}{2}\right)^{2}+\tau_{w}^{2}}=f_{c t}
$$

For this load level, point $\mathrm{P}_{\mathrm{f}}$ inside the flanges will not be cracked, since its normal stress is equal to that in the web, $\sigma_{x f}=\sigma_{x w}$, but its shear stress, $\tau_{f}=\tau_{w} \cdot b_{w} / b_{v}$. is lower than in the web, due to its bigger width (note than the effective flange width, $b_{v}$, is used). A higher load will be necessary to crack the flanges. Nevertheless, sometimes, while the load increases, the crack propagates horizontally along the web-flanges joint due to the longitudinal shear stresses at that joint produced by the shear lag. Assuming that the load which produces the initiation of cracking inside the flanges is $\lambda$ times the load which produces cracking at point $\mathrm{P}_{\mathrm{w}}$, the normal and shear stresses generated by this load at point $\mathrm{P}_{\mathrm{f}}$ inside the flanges are:

$$
\sigma_{x f}=\lambda \sigma_{x w} \quad ; \quad \tau_{f}=\tau_{w} \lambda \frac{b_{w}}{b_{v}}
$$


Then, the principal tensile stress will reach the concrete tensile strength, $\sigma_{l, f}=f_{c t}$ :

$$
\sigma_{1, f}=\frac{\sigma_{x f}}{2}+\sqrt{\left(\frac{\sigma_{x f}}{2}\right)^{2}+\tau_{f}^{2}}=\lambda\left[\frac{\sigma_{x w}}{2}+\sqrt{\left(\frac{\sigma_{x w}}{2}\right)^{2}+\left(\tau_{w} \frac{b_{w}}{b_{v}}\right)^{2}}\right]=f_{c t}
$$

The angle of a crack can be approximated, according to the theory of elasticity, as the angle which forms the principal compression stress with the longitudinal $\mathrm{x}$-axis, which is given, assuming $\sigma_{y}=0$, by $\cot (\theta)=\tau / \sigma_{1}$. Then, the ratio between the angles of inclination of the web and flanges cracks, $R_{\theta}$ will be:

$$
R_{\theta}=\frac{\cot \theta_{f}}{\cot \theta_{w}}=\frac{\tau_{f} \sigma_{1 w}}{\tau_{w} \sigma_{1 f}}=\frac{\lambda \tau_{w} b_{w}}{\tau_{w} b_{v}} \frac{\sigma_{1 w}}{\sigma_{1 f}}=\lambda \frac{b_{w}}{b_{v}} \frac{\sigma_{1 w}}{\sigma_{1 f}}
$$

Substituting Eqs. (B.1) and (B.3) into Eq. (B.4), the following expression for factor $R_{\theta}$ is obtained (Figure B.1), which depends on $b_{w} / b_{v}$ and on the ratio between the shear and normal stresses at the considered section:

$$
R_{\theta}=\frac{\frac{\sigma_{x w}}{2}+\sqrt{\left(\frac{\sigma_{x w}}{2}\right)^{2}+\tau_{w}^{2}}}{\left[\frac{\sigma_{x w}}{2}+\sqrt{\left(\frac{\sigma_{x w}}{2}\right)^{2}+\left(\tau_{w} \frac{b_{w}}{b_{v}}\right)^{2}}\right]}=\frac{-1+\sqrt{1+\left(\frac{2 \tau_{w}}{\sigma_{x w}}\right)^{2}}}{-1+\sqrt{1+\left(\frac{2 \tau_{w}}{\sigma_{x w}} \frac{b_{w}}{b_{v}}\right)^{2}}}
$$

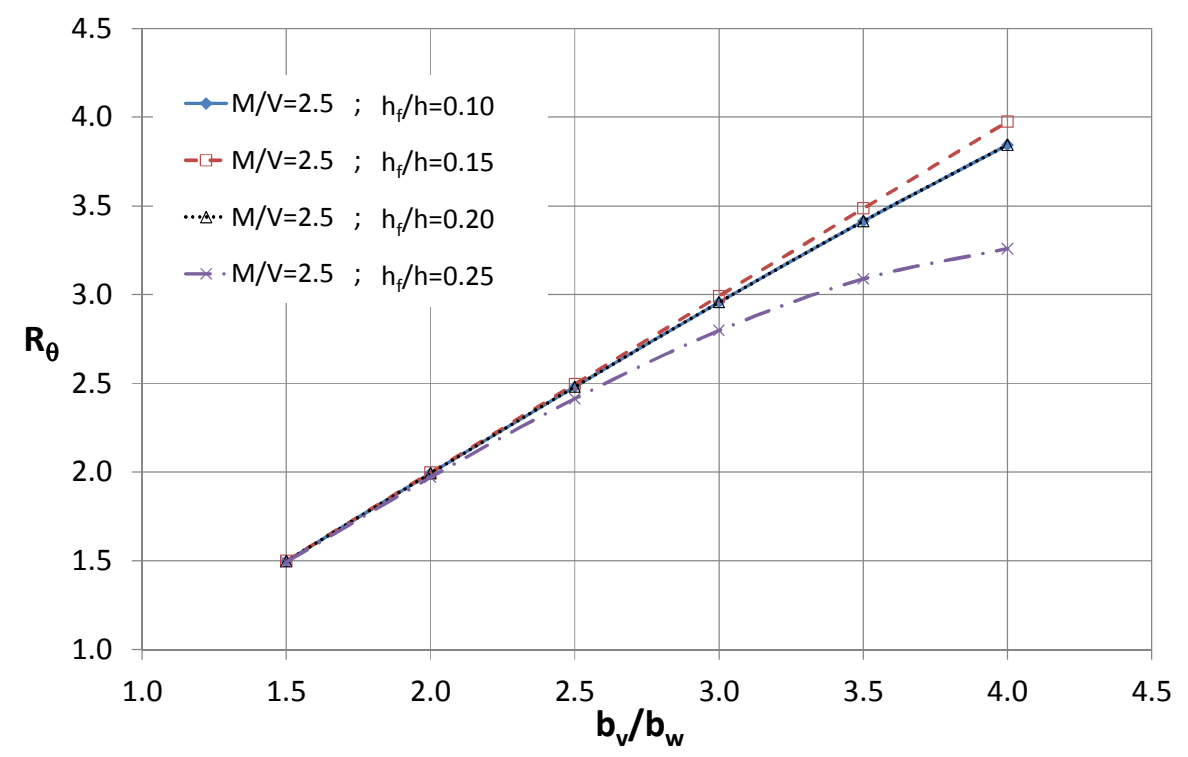

Figure B.1. Factor $R_{\theta}$ as a function of $b_{v} / b_{w}$ 
It can be observed that for T beams with ratios $h_{f} / h \leq 0.25$, factor $R_{\theta}$ can be assimilated to $b_{\Downarrow} / b_{w}$, while for beams with thicker flanges, $R_{\theta}$ is lower than $b_{\Downarrow} / b_{w}$. In this paper, a simplified value $R_{\theta}=b_{v} / b_{w}$ will be adopted, since most T-shaped beams in practice have flanges with depths that do not exceed the $25 \%$ of the total section depth.

Then, Eq. (22) can be rewritten as:

$$
\begin{gathered}
\cot \theta=\cot \theta_{w} \frac{\left(d-h_{f}\right)+\left(h_{f}-x\right) R_{\theta}}{(d-x)}=\cot \theta_{w} \frac{\left(d-h_{f}\right)+\left(h_{f}-x\right) \frac{b_{v}}{b_{w}}}{d-x}=\frac{0.85}{1-\frac{x}{d}} K_{\theta} \\
K_{\theta}=\frac{\left(d-h_{f}\right)+\left(h_{f}-x\right) \frac{b_{v}}{b_{w}}}{d-x}
\end{gathered}
$$

\section{REFERENCES}

[1] Muttoni A, Ruiz MF. Shear strength of members without transverse reinforcement as function of critical shear crack width. ACI Struct J 2008;105:163-72.

[2] Zararis PD, Papadakis GC. Diagonal shear failure and size effect in RC beams without web reinforcement. J Struct Eng 2001;127:733-42.

doi:10.1061/(ASCE)0733-9445(2001)127:7(733).

[3] Cladera A, Marí AR. Experimental study on high-strength concrete beams failing in shear. Eng Struct 2005;27:1519-27. doi:10.1016/j.engstruct.2005.04.010.

[4] Ferguson PM, Thompson JN. Diagonal Tension in T-Beams Without Stirrups. ACI J Proc 1953;49:665-75.

[5] Leonhardt F. Shear and torsion in prestressed concrete. VI FIP Congr. Prague, vol. Session IV, 1970.

[6] Kani MW, Huggins MW, Wittkopp RR. Kani on shear in reinforced concrete. Dept. of Civil Engineering, University of Toronto; 1979.

[7] Placas A, Regan PE. Shear failure of reinforced concrete beams. J Amer Concr Inst 1971;68:763-73. 
[8] Giaccio C, Al-Mahaidi R, Taplin G. Experimental study on the effect of flange geometry on the shear strength of reinforced concrete T-beams subjected to concentrated loads. Can J Civ Eng 2002;29:911-8. doi:10.1139/102-099.

[9] Ribas C, Cladera A. Experimental study on shear strength of beam-and-block floors. Eng Struct 2013;57:428-42. doi:10.1016/j.engstruct.2013.10.001.

[10] ACI-ASCE Committee 426. The Shear Strength of Reinforced Concrete Members. ACI J. Proc., vol. 70, ACI; 1973, p. 1091-187.

[11] Ribas Gonzalez CR. Resistencia a cortante de los forjados de vigueta pretensada y bovedilla. Universitat Politècnica de Catalunya. Departament d'Enginyeria de la Construcció, 2013.

[12] Celada U. Análisis de secciones en T de hormigón solicitadas a cortante y flexión construidas por fases. Tesina dirigida por Jesús Bairán. UPC-ETSECCPBDepartamento de Ingeniería de la Construcción. 2013.

[13] Mohr S, Bairán JM, Marí AR. A frame element model for the analysis of reinforced concrete structures under shear and bending. Eng Struct 2010;32:3936-54. doi:10.1016/j.engstruct.2010.09.005.

[14] Swamy RN, Qureshi SA. An ultimate shear strength theory for reinforced concrete T-beams without web reinforcement. Matériaux Constr 1974;7:181-9.

[15] Kotsovos MD, Bobrowski J, Eibl J. Behaviour of reinforced concrete T-beams in shear. Struct Eng Part B R\&D Q 1987;65 B:1-10.

[16] Hoang CL. Shear strength of non-shear reinforced concrete elements: Part 1Statically indeterminate beams. 1997.

[17] Tureyen AK, Frosch RJ. Concrete Shear Strength: Another Perspective. ACI Struct J 2003;100:609-15.

[18] Zararis IP, Karaveziroglou MK, Zararis PD. Shear strength of reinforced concrete T-beams. ACI Struct J 2006;103:693-700.

[19] Wolf TS, Frosch RJ. Shear design of prestressed concrete: A unified approach. J Struct Eng 2007;133:1512-9. doi:10.1061/(ASCE)07339445(2007)133:11(1512).

[20] Bairán JM, Marí AR. Multiaxial-coupled analysis of RC cross-sections subjected to combined forces. Eng Struct 2007;29:1722-38. doi:10.1016/j.engstruct.2006.09.007.

[21] Marí A, Cladera A, Oller E, Bairán J. Shear design of FRP reinforced concrete beams without transverse reinforcement. Compos Part B Eng 2014;57:228-41. doi:10.1016/j.compositesb.2013.10.005. 
[22] Marí A, Bairán JM, Cladera A, Oller E, Ribas C. Shear-flexural strength mechanical model for the design and assessment of reinforced concrete beams. Struct Infrastruct Eng 2014;DOI: 10.10. doi:10.1080/15732479.2014.964735.

[23] Marí A, Cladera A, Bairán J, Oller E, Ribas C. Shear-flexural strength mechanical model for the design and assessment of reinforced concrete beams subjected to point or distributed loads. Front Struct Civ Eng 2014. doi:10.1007/s11709-014-0081-0.

[24] Cladera A, Marí AR. Shear design procedure for reinforced normal and highstrength concrete beams using artificial neural networks. Part I: Beams without stirrups. Eng Struct 2004;26:917-26. doi:10.1016/j.engstruct.2004.02.010.

[25] Cladera A, Marí AR. Shear design procedure for reinforced normal and highstrength concrete beams using artificial neural networks. Part II: Beams with stirrups. Eng Struct 2004;26:927-36. doi:10.1016/j.engstruct.2004.02.011.

[26] Karayannis CG, Chalioris CE. Shear tests of reinforced concrete beams with continuous rectangular spiral reinforcement. Constr Build Mater 2013;46:86-97. doi:10.1016/j.conbuildmat.2013.04.023.

[27] Collins MP, Bentz EC, Sherwood EG, Xie L. An adequate theory for the shear strength of reinforced concrete structures. Mag Concr Res 2008;60:635-50.

[28] Tung ND, Tue NV. A new approach to shear design of slender reinforced concrete members without transverse reinforcement. Eng Struct 2015. doi:10.1016/j.engstruct.2015.04.015.

[29] Park HG, Kang S, Choi KK. Analytical model for shear strength of ordinary and prestressed concrete beams. Eng Struct 2013;46:94-103. doi:10.1016/j.engstruct.2012.07.015.

[30] Kupfer HB, Gerstle KH. Behavior of concrete under biaxial stresses. J Eng Mech Div 1973;99:853-66.

[31] Fédération Internationale du Béton. fib Model Code for Concrete Structures 2010. vol. 1. Ernst \& Sohn; 2013.

[32] Wittmann FH. Crack formation and fracture energy of normal and high strength concrete. Sadhana 2002;27:413-23.

[33] Cladera A, Marí AR. Shear design of prestressed and reinforced concrete beams. Mag Concr Res 2006;58:713-22. doi:10.1680/macr.2006.58.10.713.

[34] Leonhardt F, Walther R. The stuttgart shear tests. Cem Concr Assoc Transl Artic Bet - Und Stahlbetonbau Vol 56, N 121961 Vol 57 Ns 2, 3, 6, 7 Y 8 1962, No 111, 19611962. 
[35] Paulay T, Loeber PJ, Mattock AH, Taylor HPJ, Scordelis AC, Ngo D, et al. Shear in reinforced concrete, Volumes 1 and 2. Shear Reinf Concr, Am Concr Inst (Publ SP-42); 1974.

[36] Leonhardt F. Reducing the shear reinforcement in reinforced concrete beams and slabs. Mag Concr Res 1965;17:187-98. doi:10.1680/macr.1965.17.53.187.

[37] European Committee for Standardization (CEN). Eurocode 2: Design of Concrete Structures: Part 1: General Rules and Rules for Buildings. European Committee for Standardization; 2002.

[38] Al-Alusi AF. Diagonal tension strength of reinforced concrete T-beams with varying shear span. ACI J Proc 1957;53:1067-77.

[39] Taylor MA, El-Hammasi S. Web cracking behavior of beams using welded wire fabric as shear reinforcement. ACI J Proc 1980;77:12-7.

[40] Palaskas MN, Attiogbe EK, Darwin D. Shear strength of lightly reinforced Tbeams. J Am Concr Inst 1981;78:447-55.

[41] Reineck K-H, Bentz E, Fitik B, Kuchma DA, Bayrak O. ACI-DAfStb Databases for Shear Tests on Slender Reinforced Concrete Beams with Stirrups. ACI Struct J 2014;111:1147-56.

[42] ACI-Committee-318. Building Code Requirements of Structural Concrete and Commentary. 2011. ACI; 2011.

[43] Pujol Sánchez M, Oller Ibars E, Marí Bernat AR. Contribución del refuerzo externo transversal con laminados de polímeros reforzados con fibras a la resistencia a cortante. VI Congr. Int. Estructuras, vol. Resúmenes , 2014, p. 57-8. 


\section{Figure captions}

Figure 1. Uncoupled resistant mechanisms: A) Flexure. B) Shear.

Figure 2. Cracking prior to failure and at failure in a rectangular beam with web reinforcement (photographs from the authors) [3].

Figure 3. Comparison between T-shaped section beam and rectangular beam. A)

Sections. B) Crack pattern scheme of a rectangular beam. C) Crack pattern scheme of a $\mathrm{T}$ beam.

Figure 4. Effect of flange width, adapted from [10], based on an experimental campaign published in [7].

Figure 5. Analysis of a rectangular beam section subjected to an increasing shear forces and bending moments using the coupled model proposed by Bairán and Marí [20].
A) Shear forces vs. shear strains.
B) Shear stress distribution at flexural cracking.
C) Shear stress distribution after yielding of the longitudinal reinforcement.

Figure 6. A) Shear transfer mechanisms considered. B) Equilibrium. Adapted from [23].

Figure 7. Position of the shear critical section in the beam. Adapted from [22].

Figure 8. Considered distributions of stresses at the un-cracked concrete chord. Adapted from [22].

Figure 9. Shear stresses at high load levels in a T-shaped section. Adapted from [11].

Figure 10. Effective width in a I-shaped section.

Figure 11. Scheme of cracking in a beam with T section $\left(x \leq h_{f}\right)$.

Figure 12. Neutral axis depth in a T section. A) $x \leq h_{f}$. B) $x>h_{f}$.

Figure 13. Inclined crack with two branches in beams with $\mathrm{T}$ section.

Figure 14. Concrete chord contribution to shear strength for different $\mathrm{T}$ or rectangular beams.

Figure 15. Correlation between the prediction and the experimental results in terms of the ratio of flange to effective depths $\left(h_{f} / d\right)$.

Figure 16: Horizontal projection of the first branch of the flexural-shear critical crack for four beams tested by the authors $[3,43]$.

Figure B.1. Factor $R_{\theta}$ as a function of $b_{v} / b_{w}$. 


\section{Table captions}

Table 1. Summary of simplified expressions for rectangular beams of dimensionless shear contributing components [22].

Table 2. Summary of simplified expressions for rectangular or T beams of dimensionless shear contributing components.

Table 3. Verification of different procedures for $\mathrm{T}$ and $\mathrm{I}$ beams with and without stirrups. 